\title{
On selection-regulated population dynamics in birds and mammals
}

\author{
LARS WiTTING \\ Greenland Institute of Natural Resources, Box 570, DK-3900 Nuuk, Greenland
}

\begin{abstract}
I use the North American Breeding Bird Survey (Sauer et al. 2017) to construct 462 population trajectories with about 50 yearly abundance estimates each. Applying AIC model-selection, I find that selection-regulated population dynamics is 25, 000 (95\%:0.42-1.7e17) times more probable than density-regulated growth. Selection is essential in $94 \%$ of the best models explaining $82 \%$ of the population dynamics variance across the North American continent. Similar results are obtained for 111,215 , and 420 populations of British birds (BTO 2020), Danish birds (DOF 2020), and birds and mammals in the Global Population Dynamic Database (GPDD 2010).

The traditional paradigm - that the population dynamic growth rate is a function of the environment, with maximal per-capita growth at low population densities, and sub-optimal reproduction from famine at carrying capacities with strong competition for limited resources - is not supported. Selection regulation generates a new paradigm where the world is green and individuals are selected to survive and reproduce at optimal levels at population dynamic equilibria with sufficient resources. It is only the acceleration of the population dynamic growth rate, and not the growth rate itself, that is determined by the densitydependent environment, with maximal growth occurring at the densities of the population dynamic equilibrium.
\end{abstract}

Keywords: Population dynamics, density regulation, natural selection, life history evolution, Breeding Bird Survey, animal abundance

\section{Introduction}

Density dependence and natural selection regulate the dynamics of natural populations, preventing a continued increase in abundance. Selection regulation was nevertheless ignored when the theory of population dynamics was developed. The Malthusian law of exponential growth (Malthus 1798), the hypothesis of densityregulated growth (Verhulst 1838; Pearl and Reed 1920; Lotka 1925), and the inter-specific equations of competition and predation (Lotka 1925; Volterra 1926) are all based on the assumption that natural selection does not affect population dynamics. One of - if not the - most fundamental implication of this is the assumption that the population dynamic growth rate $(r)$ is a densityregulated function $[r=f(\epsilon)]$ of the environment $\epsilon$, with $\epsilon$ including resources, predation, and intra-specific and inter-specific competition.

The more general dynamics, where populations respond also to natural selection, behave quite differently. For a hypothetical ecological vacuum - with no intra-specific and inter-specific interactions - there is a constant frequency-independent selection where the quality-quantity trade-off [where a given amount of energy can produce many competitively inferior or few competitively superior offspring (Smith and Fretwell 1974; Stearns 1992)] selects for an accelerating average growth rate and a hyper-exponentially increasing population (Witting 1997, 2000a).

Natural populations with interactive competition generate a density-frequency-dependent resource bias in favour of the competitively superior individuals that trade-off replication for increased quality. This bias selects for decelerating growth, with increased deceleration as the level of interactive competition increases with increased abundance (Witting 1997, 2000b). The realised acceleration of the growth rate is determined by the strength of the competition driven selectiondeceleration relative to the quality-quantity driven selection-acceleration, with exponential growth occurring when the opposing forces are equally strong. This is the case at the population dynamic equilibrium abundance, where the non-accelerating exponential growth rate may be zero, but also positive or negative; with population dynamic equilibrium occurring only when the growth rate is zero.

Across a wider range of densities, it follows that the density-frequency-dependence of interactive competition imposes population dynamic feedback selection for accelerating growth below the equilibrium abundance, and for decelerating growth above. The resulting population dynamics is cyclic, and it has been referred to as inertia and selection-delayed dynamics in earlier publications (Witting 1997, 2000a,b, 2002).

The inclusion of natural selection in population dy- 
namics implies a change of concept, where it is no longer possible to determine the growth rate, but only the acceleration of the growth rate $[d r / d t=f(\epsilon)]$ as a function of the environment [argued also by Ginzburg (1972, 1998) for other reasons]. The change is clear on theoretical grounds (Witting 1997, 2000b), but how important is it in natural populations?

Selection regulation might be so weak that traditional ecology is a fair approximation. An additional component like selection, however, is indeed necessary to explain the cyclic dynamics of forest insects (Ginzburg and Taneyhill 1994; Witting 1997, 2000b), as well as the delayed recovery of large whales following the commercial exploitation in past centuries (Witting 2003, 2013). There is an increasing number of eco-evolutionary studies documenting evolutionary dynamics on ecological timescales (e.g., Thompson 1998; Law 2000; Sinervo et al. 2000; Witting 2000b; Hairston et al. 2005; Saccheri and Hanski 2006; Coulson et al. 2011; Schoener 2011; Turcotte et al. 2011; Hendry 2017; Brunner et al. 2019), including cases of evolutionary rescue where natural selection accelerates the growth rate turning a population decline into a hyper-exponential increase (Gomulkiewicz and Holt 1995; Agashe 2009; Bell and Gonzalez 2009; Ramsayer et al. 2013; Bell 2017).

I aim for the first large-scale comparison where the population dynamic effects of feedback selection are estimated relative to that of density regulation across hundreds of species. My main focus is on North American birds where I found the best data (Sauer et al. 2017), with results being cross-validated against British birds (BTO 2020), Danish birds (DOF 2020), and birds and mammals in the Global Population Dynamic Database (GPDD 2010). It is this level of analysis that is necessary to identify if it is essential to abandon density-regulated growth and move to selectionregulated population dynamic equations with accelerating and decelerating growth rates.

For my analysis I use several population dynamic models, with the age-structure of each species given by the equilibrium life history estimates of Witting (2021c). For each population of each species, I develop an exponential, hyper-exponential, density-regulated and selection-regulated model, and determines the bestfitting-hypothesis by the Akaike information criterion (AIC, Akaike 1973) to trade-off the increasing number of parameters (from 2 to 5 ) against the likelihood of each model. This allows me to access the relative probability of selection versus non-selection dynamics, and for cases where the selection-regulated model is preferred it allows also for a quantitative comparison between the strengths of selection regulation and density regulation.

\section{Data}

For a firm comparison I need long-term abundance data across a multitude of species, but these are hardly ever available. The North American Breeding Bird Survey (BBS) is an exception where thousands of skilled birders have counted breeding birds by a standardised method across the states of USA and Canada every year since 1966 (Sauer et al. 2017). This survey is conducted by volunteers, and it is one of - if not thelarges monitoring of wildlife on Earth, when measures by the joint scale of the area covered, the number of species involved, and the number of years with continued counting. The 2020 dataset that I analyse contain observations of 664 species/subspecies on a total of 5,210 survey routes across 62 states in North America, with approximately 2,500 routes being surveyed each year.

The BBS have been analysed in many ways for a variety of purposes (e.g., Robbins et al. 1986; Link and Sauer 1998; Link and Sauer 2002; Sauer et al. 2003; Smith et al. 2014; Niemuth et al. 2017; Hudson et al. 2017; Rosenberg et al. 2017; Sauer et al. 2017; Link et al. 2020). I combine traditional index estimation with a maximum likelihood based spatial clustering routine to partition the dynamics of each species into populations with different trajectories.

To cover the majority of the BBS survey routes I use a spatial model with a $15 x 7$ longitudinal/latitudinal grid (top plot in Fig. 1; excluding only the North with few routes). I use the BBS that cover this area from 1966 up to and including 2019. The data are organised in different routes, with each route having 50 point-counts placed $0.8 \mathrm{~km}$ apart. For each point, the observer conducts a 3 min count of all the birds heard or seen within $400 \mathrm{~m}$. Some of the counts are marked as unreliable due to, e.g., bad weather, and I use only the reliable counts.

\subsection{Index time-series}

To estimate index time-series of relative density (relative number of individuals per unit area) for the different populations, I divided routes between the different observers to eliminate effects from variation in observation skills (Sauer et al. 1994). For each observer specific route, I removed the first year of the time-series because the observation efficiency is often reduced in that year (Kendall et al. 1996). I include zero observations; however, I exclude an observer specific time-series of a specific species if the observer had observed that species 

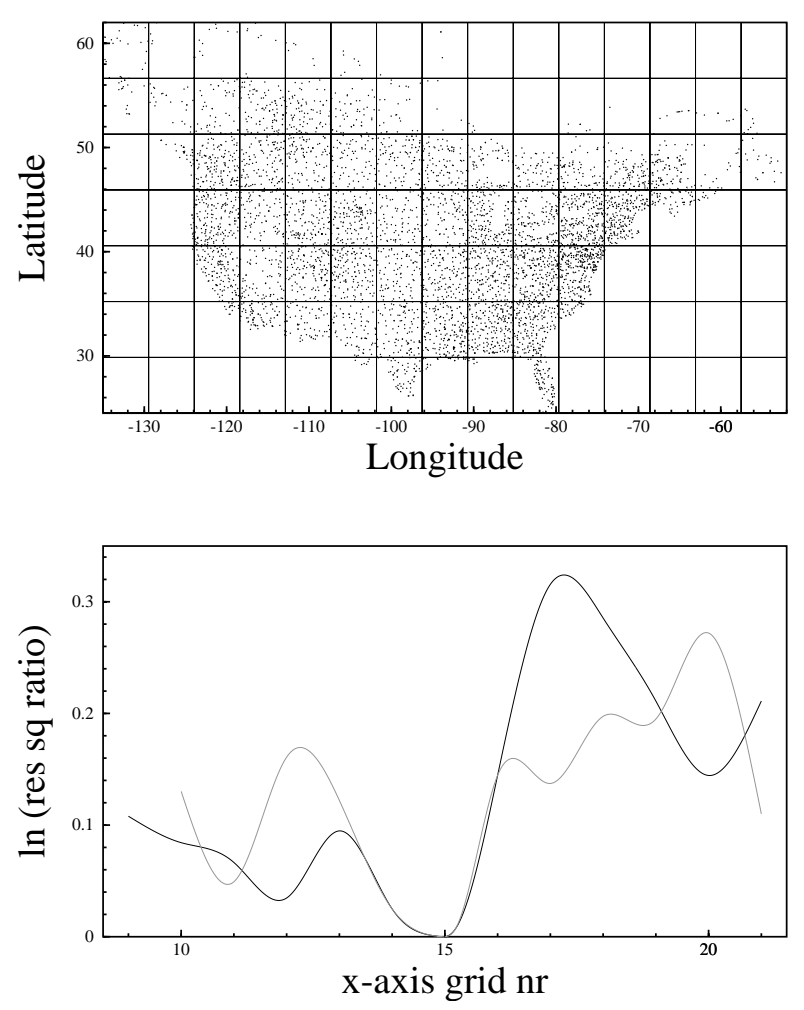

Figure 1: Spatial model. Top: The geographical distribution of the study, with the survey routes of the North American Breeding Bird Survey shown by dots, and the grid of the spatial model shown by lines. Bottom: $\mathrm{Cu}-$ bic spline interpolation curves for the natural logarithm of the $\bar{\epsilon}(x: y) / \epsilon(15: 7)$-ratio for the average squared residual across all estimated populations, with $x: y$ being the grid size of the spatial model, with the most accurate index series following form the $15: 7$-grid used in the top plot. The black curve reflects a $x: y=x: x / 2$-grid, and the grey curve a $x: y=x: 7$-grid.

in less than $30 \%$ of the years in the time-series. Based on a total of 6.18 mill. observations of at least one individual of one of the 664 species/subspecies observed during the BBS, this generated a set of 18,700 observer specific time-series with observations of a multitude of species. These time-series were then used to calculate the index time-series of relative population densities for different areas.

For a species in a given area, I used the $n_{r, t}=$ $1+\sum n_{r, p, t}$ sum of the 50 point counts (subscript $p$ ) per year (subscript $t$ ) as a relative population density measure for an observer specific route $(r)$, with the timeseries of relative density covering all years with point counts by the observer on the route. These route counts were combined to produce index series of relative den- sities for each of the grid-squares where a species was observed, as well as for larger areas containing multiple neighbouring grid-squares, including the whole North America as the largest population.

The index time-series were calculated to reflect the development in the geometric mean of the relative population density across all the routes in an area, with the developments of relative density being calculated separately for each route. For this let

$$
\tilde{n}_{r, t}=\gamma_{r} n_{r, t}
$$

be the relative density of route $r$ in year $t$, with

$$
\gamma_{r}=\tilde{n}_{t 0 \mid r} / n_{r, t 0 \mid r}
$$

being the multiplicative scaling parameter for route $r$, with $t 0 \mid r$ being the first year with a positive count of the species on route $r$ (zero counts prior to $t 0 \mid r$ did not affect the overall index), and $\tilde{n}_{t 0 \mid r}$ being the overall index estimate in that year, with the index value for the initial year being $\tilde{n}_{t 0}=1$, and subsequent index estimates calculated as

$$
\tilde{n}_{t}=\exp \left[\frac{1}{n} \sum_{r=1}^{n} \ln \tilde{n}_{r, t}\right]
$$

with $n$ being the number of routes covered in the area in year $t$, and the error coefficient of variation of the index estimate in year $t$ being calculated from the variation in the index across all the routes with data on the given species in that year. After an index series was constructed across all years, it was rescaled to make the index value of unity correspond with the geometric mean of the time-series.

The first year of an index time-series was the first year where a species was observed on at least 10 routes, and a final index series for an estimated population would not be used unless the number of observations of at least one individual was at least 30 on average across all years.

\subsection{Population dynamic clustering}

To geographically delineate the data into trajectories of more or less independent populations, I develop a maximum likelihood routine that clusters the correlated dynamics of neighbouring areas. The method uses the principle that the spatial geographical synchronisation - and thus correlation - of population dynamics is strongest in the areas that drive the dynamics, with synchronisation and correlation deteriorating at the boundaries where the uncorrelated dynamics of different populations meet. I use the clustering routing 

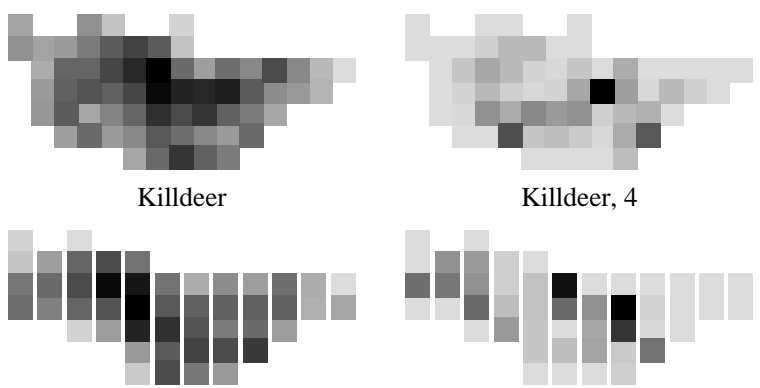

Eastern Kingbird

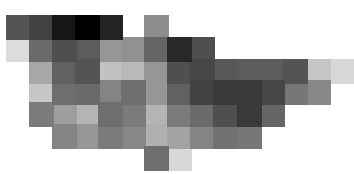

Chipping Sparrow

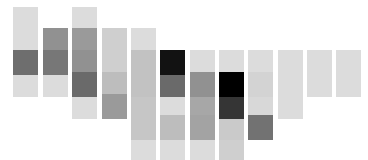

Eastern Kingbird, 5

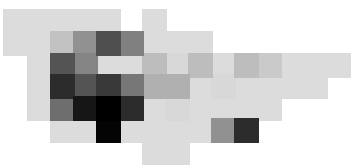

Chipping Sparrow, 4

Figure 2: Density \& synchronisation. Three cases showing the spatial distribution of relative population density (left plots; rescaled number of individuals per observation) and the local synchronisation of population dynamics (right plots; rescaled $\bar{L}$ ), with density and synchronisation increasing with darkness. Eastern kingbird has five, and chipping sparrow and purple martin four local synchronisation maxima.

to divide the spatial dynamics of each species into populations with separate distributions and trajectories.

Having an initial set of index time-series for all the grid-squares where a species was observed, I calculated the synchronisation of the population dynamics between two population components-like grid-squares $i$ and $j$-using a log-normal likelihood

$$
\ln L_{i, j}=-\sum_{t} \frac{\left[\ln \left(\tilde{n}_{i, t} / \tilde{n}_{j, t}\right)\right]^{2}}{2 c v_{t}^{2}}+\ln c v_{t}
$$

with $\ln L$ increasing monotonically with the synchronisation of the trajectories, $\tilde{n}_{i, t}$ and $\tilde{n}_{j, t}$ being the index estimates of the $i$ th and $j$ th population components in year $t$, and $c v_{t}=\sqrt{c v_{i, t}^{2}+c v_{j, t}^{2}}$ being the error coefficient of variation calculated from the coefficients of variation of both components.

I could then, for each population component $i$ calculate the average population dynamic synchronisation with neighbouring population components $j$

$$
\ln \bar{L}_{i}=\frac{1}{n} \sum_{j \neq i} \ln L_{i, j}
$$

with $n$ being the number of neighbouring components for population component $i$. When plotted as a map (Fig. 2), the average synchronisation identifies the local maxima where the synchronisation of the population

dynamics with the neighbouring components are larger than in the surrounding areas. The set of local maxima was then used as starting points for a population dynamic clustering routine.

The initial set of populations for a species contained the single-square local maxima populations only, and I used a clustering routine to extend the geographical distributions of these populations until they met their natural population dynamic boundaries. For this I would for all the identified populations of a species calculate their dynamic synchronisation (eqn 4) with all of their neighbouring areas, as long as these were not already contained in an identified population. I would then identify the area with the highest synchronisation to one of the identified populations, and join the area to its neighbouring population if - and only if - the dynamics of the area was more synchronised with that population than to any of the other identified populations. If this was not the case, I would proceed with the area with the next highest level of synchronisation with a neighbouring population, until it was either possible to join a small area with a neighbouring population or there were no extra neighbouring areas available.

If it was possible to join a neighbouring area with a population, I would recalculate the index time-series for that population, and recalculate all the synchronisations between populations and their neighbouring grid-squares, and rerun the clustering routine. If on the other hand, it was impossible to find a match, I would increase the size of the non-population areas to two neighbouring grid-squares, calculate the index series of these two-grid-square components, and rerun the clustering procedure with the two-grid-square components. This increase in the number of grid-squares in the neighbouring components would continue until it was possible to join a multi-grid-square component with a population, or until it was no longer possible to find a neighbouring component with the desired number of grid-squares. If the latter was the case, the clustering routine would stop. If on the other hand, it was possible to join a multi-grid-square component with one of the identified populations, I would do that and reset the clustering routine to a comparison between single grid-square neighbours and the identified populations, continuing the process until it was no longer possible to find a single or multi-grid-square component to include into one of the identified populations.

This clustering routine produces at set of single/multi-grid-square populations from the local synchronisation maxima on the geographical grid of areas, with the boundaries between the populations being the areas with lowest population dynamic 
synchronisation. Yet, as the identification of the populations and their boundaries is driven by relative differences in synchronisation, the population dynamics of the identified populations could be quite similar; with the identified structuring of some species being a relatively large set of populations with quite similar dynamics between some of the populations. I thus structured the identified population units into populations and sub-populations.

To differentiate between populations and subpopulations, I joined neighbouring population units where the correlation coefficient between the dynamics of the two units were larger than 0.7. The population units that remained after this clustering were classified as populations, with the population units of the joined populations being classified as sub-populations.

A potential problem for the clustering routine relates to populations that use two or more neighbouring gridsquares dependent upon yearly fluctuations in the environment. This will induce some negative correlation between the index estimates of the grid-squares, and this might - at least potentially - prevent the relevant grid-squares from being identified as a single population dynamic cluster. To minimise this effect of year-to-year fluctuations, and to focus more on the underlying factors that control the overall shapes of the population dynamic trajectories, I used the five-year running mean of the index time-series in the statistical calculations of synchronisation and correlation. The final index series were the raw series with no smoothing.

Another issue is the spatial resolution of the data. If the underlying grid has too small grid-squares, the estimated index series of the different squares would be so noisy that we cannot trust the estimated local similarity maxima. The clustering routine would then tend to identify too many populations where the differences in the estimated trajectories reflect observation uncertainty rather than differences in the underlying population dynamics. If on the other hand the grid-squares are too large, the spatial resolution would be too small to differentiate populations.

To identify the optimal grid size for the clustering routine, I used the average squared residual

$$
\epsilon=\frac{1}{t_{l}-t_{0}} \sum_{t=t_{0}}^{t_{l}} \ln \left(\tilde{n}_{t} / \hat{n}_{t}\right)^{2}
$$

between the index series $\left(\tilde{n}_{t}\right)$ and its five-year running mean $\left(\hat{n}_{t}\right)$ as an estimate of the uncertainty in the estimated trajectories. I could then for different grid sizes calculate the average $\epsilon(\bar{\epsilon})$ across the index series that were estimated for all the populations that were identi- fied by the clustering routing across all species. I then minimised $\bar{\epsilon}$ by changing the grid size to find that the most accurate (i.e., least year-to-year fluctuating) index series were estimated by a $15 x 7$ longitudinal/latitudinal grid (Fig. 1; bottom plot).

\subsection{Population trajectories}

A total of 626 local maxima $\left(\ln \bar{L}_{a}^{*}\right)$ in the synchronisation of population dynamics were identified across 299 species of North American birds that passed the minimum data criterion for population delineation.

The population dynamic clustering routine failed to identify explicit geographically distributed populations for 139 species; usually because there was only a single local synchronisation maximum. For cases with two or more local maxima, the routine identified a single population for 60 species, two populations for 59 species, three populations for 24 species, four populations for 12 species, and five populations for five species.

In all I obtained 323 population level time-series with identified boundaries, and 139 time-series at the level of North America with no explicitly identified boundaries. The geographical distributions and index timeseries for forty species are plotted in Figs. 3, with the population delineations of all species plotted in Supplementary Information S1. All estimated time-series at the population and sub-population level are listed in Supplementary Information S2 and described in Supplementary Information S3.

\subsection{BTO, DOF, \& GPDD data}

I analyse also population trajectories compiled by others, including 215 index trajectories for summer and winter birds in Denmark with yearly estimates from 1976 to 2019 (DOF 2020), 111 index trajectories for British birds with yearly estimates from 1994 to 2019 (BTO 2020), and 420 bird and mammal trajectories of varying length and quality from the Global Population Dynamic Database (GPDD 2010; excluding low quality data). Owing to the amount of underlying raw data, the length of the different surveys, and the varying quality of the trajectories in the GPDD, I analyse the BBS and check whether the overall conclusions for North American birds hold for the other areas also. 
bioRxiv preprint doi: https://doi.org/10.1101/2021.11.27.470201; this version posted November 27, 2021. The copyright holder for this preprint (which was not certified by peer review) is the author/funder, who has granted bioRxiv a license to display the preprint in perpetuity. It is made available under aCC-BY-NC-ND 4.0 International license.

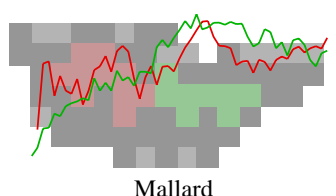

Mallard

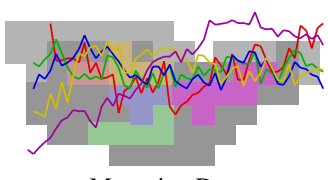

Mourning Dove

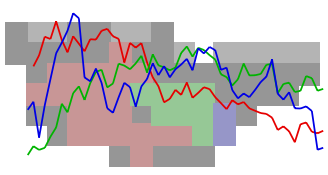

Killdeer

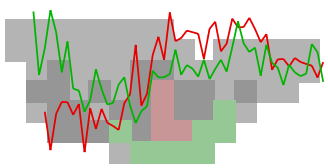

Great Egret

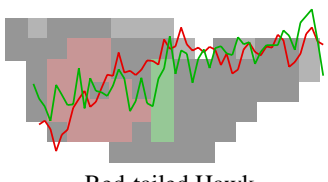

Red-tailed Hawk

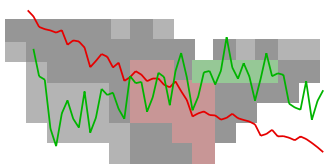

Yellow-shafted Flicker

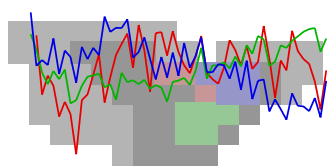

Great Crested Flycatcher

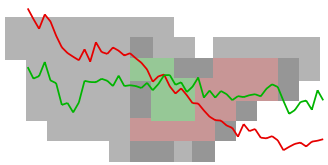

Eastern Wood-Pewee

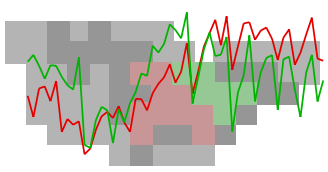

Eastern Phoebe

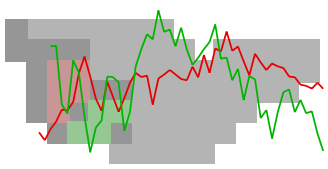

Steller's Jay

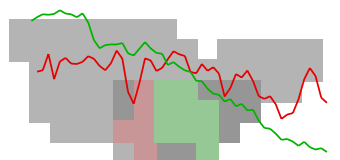

Northern Bobwhite

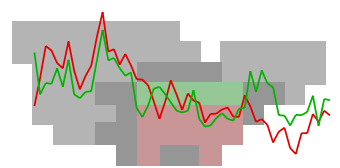

Yellow-billed Cuckoo

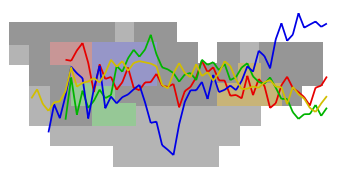

Wilson's Snipe

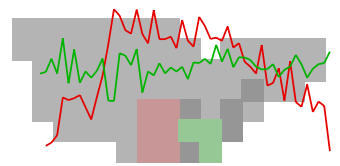

Little Blue Heron

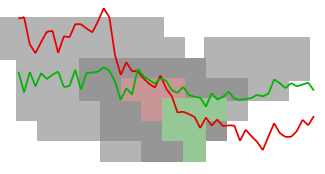

Red-headed Woodpecker

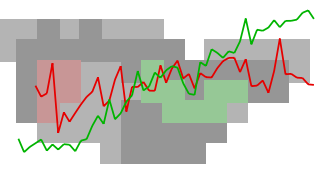

Pileated Woodpecker

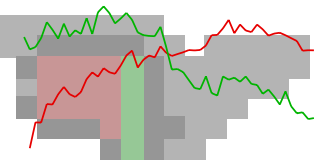

Western Kingbird

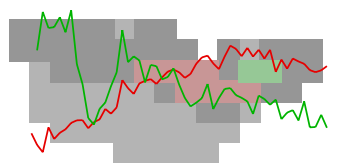

Alder Flycatcher

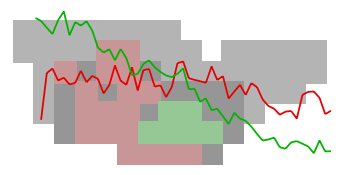

Loggerhead Shrike

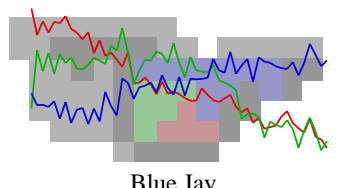

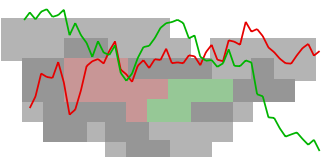

Ring-necked Pheasant

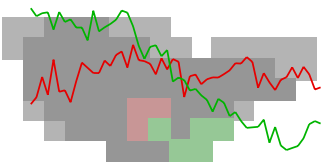

Common Nighthawk

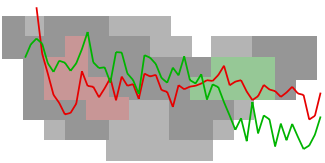

Spotted Sandpiper

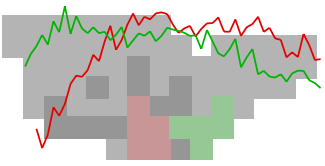

Cattle Egret

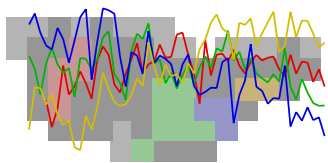

Downy Woodpecker

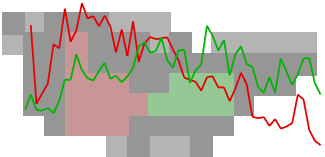

American Kestrel

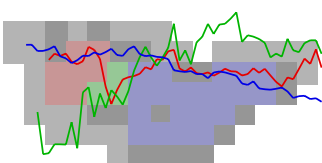

Eastern Kingbird

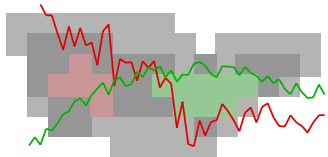

Willow Flycatcher

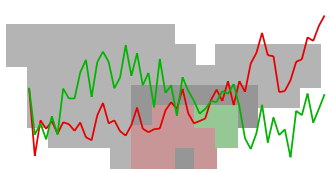

White-eyed Vireo

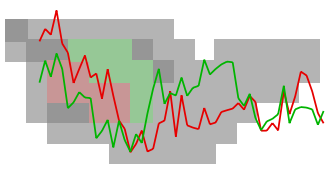

Black-billed Magpie

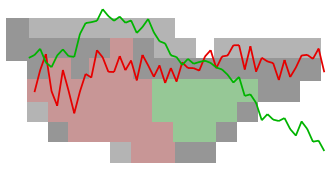

Rock Pigeon

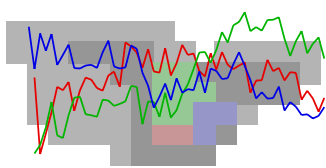

Ruby-throated Hummingbird

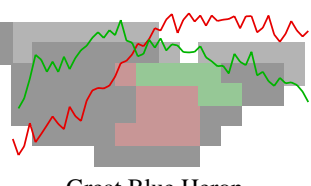

Great Blue Heron

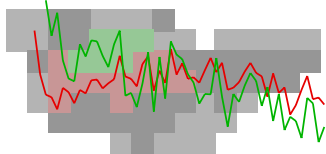

Northern Harrier

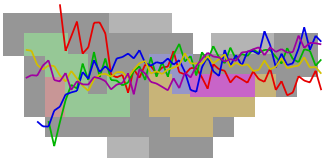

Hairy Woodpecker

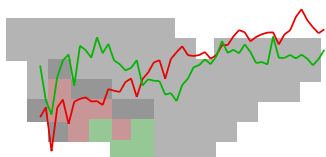

Ash-throated Flycatcher

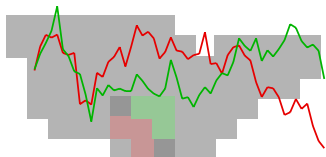

Scissor-tailed Flycatcher

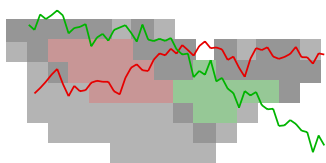

Least Flycatcher

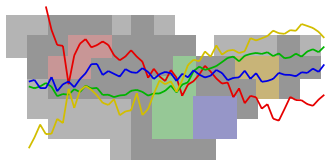

Red-eyed Vireo

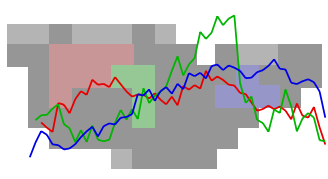

American Crow

Figure 3: Population delineation in forty species as estimated by the clustering routine, with colours separating the distributions and index trajectories of the different populations. Dark grey mark areas that were not selected by the clustering routine or selected but with less than 50 observations per year. All delineations are plotted in Supplement S1, with the estimated index trajectories listed Supplement S2 and S3. 


\section{Population models}

Selection-regulated dynamics is based on densityregulated growth

$$
n_{\tau+1}=n_{\tau} \lambda_{\tau}\left(n_{\tau} / n^{*}\right)^{-\gamma}
$$

except that the intrinsic growth rate $\left(\lambda_{\tau}\right)$ evolves

$$
\lambda_{\tau}=\lambda_{\tau-1}\left(n_{\tau-1} / n^{*}\right)^{-\gamma_{\iota}}
$$

by the population response to the density-frequencydependent selection of intra-specific interactive competition (Witting 1997, 2000b, 2013), where

$n_{\tau}:$ is the abundance in generation $\tau$,

$n^{*}$ : the population dynamic equilibrium,

$\gamma$ : the strength of density regulation, and

$\gamma_{\iota}$ : the selection response that operates as a densitydependent effect with a delay of approximately one generation.

For this article I use age-structured models that are parameterised by the average birth rate $\left(m^{*}\right)$ of mature females at population dynamic equilibrium, the average age of reproductive maturity $\left(a_{m}^{*}\right)$, and the yearly survival $p$ of individuals older than one year of age. Following the life history model of Witting (2017a), adult survival is interchangeable with the reproductive period $t_{r}=1 /(1-p)$, with an equilibrium per-generation growth rate of unity

$$
\lambda^{*}=l_{m} t_{r} m^{*} / 2=1
$$

where $l_{m}=2(1-p) / m^{*}$ is the probability that a newborn will survive to $a_{m}^{*}$, and the yearly survival of ageclass zero offspring is $p_{0}=l_{m} p^{1-a_{m}^{*}}$.

These life history parameters were obtained from Witting (2021c) and they were fixed for each model to reduce the number of parameters estimated by the likelihood function. The stable age-structure at equilibrium was used as the initial age-distribution, with the time-steps of model projections being shorter than the age of reproductive maturity (one or three steps per year in most cases).

The phenotypic plasticity that responds to regulation by density-dependence and/or natural selection was assumed to operate on the birth rate $\left(m=\tilde{m} / m^{*}\right)$ - and in some models also on the age of reproductive maturity $\left(a_{m}=\tilde{a}_{m} / a_{m}^{*}\right)$-with the relative parameters $\tilde{m}$ and $\tilde{a}_{m}$ being unity at equilibrium.

Exponential growth. The relative age of reproductive maturity $\left(\tilde{a}_{m}\right)$ was fixed at unity in the exponential model, making the relative birth rate $(\tilde{m})$ the only free parameter. Yet, the model has two parameters to fit, as we need an estimate of the initial abundance $\left(n_{t}\right)$ also.

Hyper-exponential growth. The relative birth rate of the hyper-exponential model is an agestructured initial condition, where the birth rate at time $t$ for individuals of age $a$ is an inverse function

$$
\tilde{m}_{a, t}=1 / q_{a, t}
$$

of the average competitive quality $(q)$ of individuals of age $a$, with $q^{*}=1$ for all $a$ representing an equilibrium with no growth. The relative age of reproductive maturity is, dependent on model version, either fixed at unity, or proportional to competitive quality

$$
\tilde{a}_{m, a, t}=q_{a, t}
$$

with $\tilde{a}_{m}=a_{m} / a_{m}^{*}$.

Competitive quality - and thus also the birth rate, and age of maturity in some models - evolve by a selection response

$$
q_{0, t}=q_{t} e^{-\gamma_{\iota}}
$$

where the average offspring quality $\left(q_{0}\right)$ is a product between the average across the mature component

$$
q_{t}=\frac{\sum_{a \mid a_{m, a} \leq a} q_{a, t} n_{a, t}}{\sum_{a \mid a_{m, a} \leq a} n_{a, t}}
$$

and a selection response $e^{-\gamma_{\iota}}$, where

$$
\gamma_{\iota}=-\sigma \partial r_{i} /\left.\partial \ln q_{i}\right|_{q_{i}=q}
$$

is a product between the intra-population selection gradient $\left[\partial r_{i} /\left.\partial \ln q_{i}\right|_{q_{i}=q}\right.$, with $i$ denoting intra-specific variation] and a phenotypic selection response $(\sigma \geq 0)$.

When there are no interactive competition and all individuals have equal access to resources, the intraspecific variation in the growth rate (i.e., natural selection fitness) is simply $r_{i}=\ln \lambda_{i} \propto-\ln q_{i}$ so that $\partial r_{i} /\left.\partial \ln q_{i}\right|_{q_{i}=q}=-1$. This is the limit case of hyperexponential growth at zero population density. Yet, for the hyper-exponential models in this paper, I allow $\gamma_{\iota}$ to take both positive and negative values to capture the somewhat broader range of options with a constantly accelerating $\left(\gamma_{\iota}>0\right)$ or decelerating $\left(\gamma_{\iota}<0\right)$ growth rate $\left(\gamma_{\iota}=0\right.$ is exponential growth).

As the selection for hyper-exponential growth is frequency-independent it follows that $r_{i} \propto-\ln q_{i}$ is proportional to the intrinsic growth rate $\hat{r}_{i}$ (i.e., the 
non-plastic component of $r$ ). The selection gradient on the per-generation growth rate is thus $\partial r_{i} /\left.\partial \ln \hat{r}_{i}\right|_{\hat{r}_{i}=\hat{r}}=$ $-\partial r_{i} /\left.\partial \ln q_{i}\right|_{q_{i}=q}$, with the selection induced acceleration or deceleration of the growth rate being

$$
\dot{r}=d \hat{r} / d t=\gamma_{\iota}
$$

The modelling of the intra-specific variation and the associated generation of selection (eqns 14 and 15), are not directly part of the population dynamic equations, as the latter operate only with the average response that is captured by eqns 12 and 13 .

While the hyper-exponential model is somewhat more complex than the exponential model, it has only a single free population dynamic parameter $\left(\gamma_{\iota}\right)$, just as the exponential mode. Yet, with two initial conditions $\left(n_{t} \& q_{t}\right.$ for all age-classes) there are three statistical parameters to fit.

Density-regulated growth. For density-regulated growth I use the Pella and Tomlinson (1969) formulation

$$
\tilde{m}=1+[\hat{m}-1]\left[1-\left(n / n^{*}\right)^{\gamma}\right]
$$

that has three free parameters (the maximum relative birth rate $\hat{m}$, the strength of density regulation $\gamma$, and the equilibrium abundance $n^{*}$ ) and one initial condition $\left(n_{t}\right)$ to estimate from data (with $\tilde{a}_{m}$ fixed at unity).

With the per-generation growth rate $(r \propto \ln \tilde{m})$ being proportional to the log of eqn 16 , we note the traditional assumption that the realised growth rate is a direct function of an assumed maximum growth rate and the density-dependent ecology.

Selection-regulated dynamics. The equations of selection-regulated dynamics include a density regulation

$$
\begin{aligned}
m_{t} & =m^{*} \tilde{m}_{t}\left(n_{t} / n^{*}\right)^{-\gamma} \\
a_{m, t} & =a_{m}^{*} \tilde{a}_{m, t}\left(n^{*} / n_{t}\right)^{-\gamma}
\end{aligned}
$$

that is formulated as a log-linear approximation of deviations from the equilibrium life history, instead of being formulated from a hypothetical maximal growth rate. The phenotypic response of eqn 17 adjusts the intrinsic birth rate from eqn 10, and in some models also the intrinsic age of maturity from eqn 11 , in accordance with the density-dependent ecology $\left(n_{t} / n^{*}\right)$.

The changes in competitive quality - and thus also by eqns 10 and 11 in the intrinsic birth rate and age of maturity - from the population dynamic feedback selection of the density-dependent interactive competition, was derived by Witting $(1997,2000 b)$ as

$$
q_{0, t}=q_{t}\left(n_{t} / n^{*}\right)^{\gamma_{\iota}}
$$

with the selection induced acceleration or deceleration of the growth rate

$$
\dot{r}=\gamma_{\iota} \ln \left(n^{*} / n_{t}\right)
$$

being a log-linear function of the density-dependent ecology.

The selection behind eqns 18 and 19 is based on the biased resource access that emerges when the competitively superior individuals monopolise resources, with the selection being frequency-dependent because the success of competition for a given variant depends on the average competitive quality of the individuals in the population. The selection is also density-dependent because the ability to monopolise resources depend on the frequency by which an individual competes against other individuals over resources.

The explicit modelling of the selection requires equations that account for the intra-population variation in competitive quality and resource access (see Witting 1997, 2000b for details). Yet, the selection produces the population level response of eqn 18, which can be incorporated directly into the population dynamic equations, selecting for an increase in average quality when the abundance is above the equilibrium, and for a decline when the abundance is below.

The population dynamics that follow from the population dynamic feedback selection is most often damped-cyclic (Appendix A). Thus, I calculate the cycle period $(T)$ and damping ratio $(\zeta)$ to characterise the dynamics. The damping ratio is zero for a stable cycle, and it increases monotonically with the damping of cyclic dynamics to a value of unity for the monotonic return of typical density-regulated growth. I calculate the damping ratio

$$
\zeta=\frac{1}{\sqrt{1+4 \pi^{2} / \delta^{2}}}
$$

by the logarithmic decrement $\delta=\ln \left(n_{p, 1} / n_{p, 2}\right)$ of the two successive abundance peaks $\left(n_{p, 1}\right.$ and $\left.n_{p, 2}\right)$ that follow from an equilibrium population that is initiated with a positive growth rate where $m_{t}=1.5 \mathrm{~m}^{*}$. The estimated period $(T)$ is the number of years between these two abundance peaks.

When the $\gamma_{\iota} / \gamma$-ratio is somewhat larger than one the dynamics become unstable with amplitudes that increase over time instead of dampening out. In these cases, I revert $n_{p, 1}$ and $n_{p, 2}$ in the estimate of $\delta=$ $\ln \left(n_{p, 2} / n_{p, 1}\right)$ and multiplies the damping ratio by minus one, so that negative $\zeta$ values refer to exploding cycles, with the rate of explosion increasing with a $\zeta$ estimate that declines from zero to minus one. 
Both versions of the selection-regulated model (with or without selection on $\left.a_{m}\right)$ have three parameters $(\gamma$, $\left.\gamma_{\iota}, \& n^{*}\right)$ and two initial conditions $\left(n_{t} \& q_{t}\right.$ for all age-classes) to estimate from the data.

\section{Model selection}

I use maximum likelihood to estimate the parameters for all models given log normally distributed abundance data

$$
\ln L=-\sum_{t} \frac{\left[\ln \left(\tilde{n}_{t} / n_{t}\right)\right]^{2}}{2 c v_{t}^{2}}+\ln c v_{t}
$$

where $\tilde{n}_{t}$ is the index estimate in year $t, n_{t}$ the model abundance in that year, and $c v_{t}=\sqrt{\tilde{c v_{t}^{2}+c v^{2}}}$ the coefficient of variation with $\tilde{c v_{t}}$ being the coefficient of the index estimate in year $t$ and $c v$ being the additional variance that is not captured by the data (with $c v$ being a fitted parameter). To search for the global maximum of a model given the data of an index trajectory, I draw 100,000 random parameter sets, applying a Quasi-Newtonian minimiser to the 100 best-fitting random sets, selecting the maximum likelihood from those 100 minimizations.

The maximum likelihood was converted to AIC $[\alpha=$ $2(k-\ln L), k$ nr. of model parameters], whereafter I use two rounds of AIC model selection. The first uses four models from exponential growth to selection-regulated dynamics to determine whether it is essential to include selection into population dynamic models or not. This round uses hyper-exponential and selection-regulated models with no regulation on age of maturity to obtain a structure that is as similar as possible to the exponential and density-regulated models. Given the distribution of the AIC-selected models I calculate the fraction of the models that include selection, and the distribution of the probability ratio $p(s / d)=e^{\left(\alpha_{s}-\alpha_{n}\right) / 2}$ of selection $(s)$ versus non-selection models $(d)$, with the $s$ and $d$ models being hyper-exponential and exponential growth when one of these are the best AICfitting model, and the $s$ and $d$ models being selectionregulated dynamics and density-regulated growth when one of these are the best model. This ratio is also transformed into a probability-like measure

$$
\tilde{p}=\left\{\begin{array}{rll}
-1 & +p(s / d) & \text { if } p(s / d) \leq 1 \\
1-1 / p(s / d) & \text { if } p(s / d)>1
\end{array}\right.
$$

that is minus one when selection models are unlikely compared with non-selection models, zero when they are equally likely, and one when non-selection models are unlikely compared with the selection models.
As the conclusion from the first round of model selection was found to be strongly in favour of selection models, I included a larger set of selection models in the aim of identifying a more optimal model for each population. Four new model versions were added to allow for a linear trend in the population dynamic equilibrium $\left.\left(n^{*}\right): i\right)$ a trend that covered the whole data period (1 extra parameter); $i$ ) a trend that started after the first data year (2 extra parameters); iii) a trend that ended before the last data year (2 extra parameters); and $i v$ ) a trend that started after the first year and ended before the last year (3 extra parameters), with a minimum allowed trend period around five years.

All selection models were fitted with and without regulation on age of maturity, producing a total set of 13 models for each population. The AIC-selected models were included for further analysis only if the mean of the residuals was not significantly different from zero $(p<0.05$ student't), there were no significant autocorrelation in the residuals (lag 1 and 2), no significant correlation between the residuals and the model projection, and the model explained more than $50 \%$ of the variance in the data.

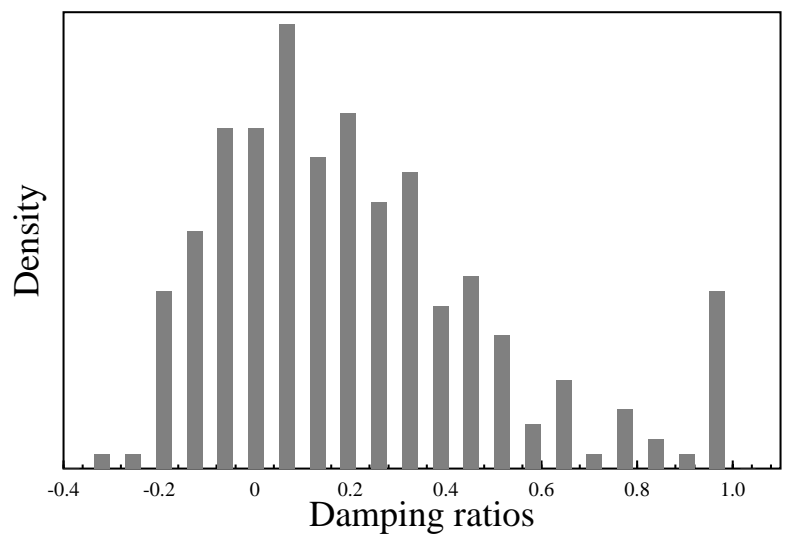

Figure 4: Damping ratios. Distribution of point estimates of damping ratios across all the AIC-selected selection-regulated and density-regulated models.

\section{Population dynamic results}

For the fitting of population dynamics I used the 323 population level time-series with identified boundaries, and the 139 time-series for North America as a whole. For 127 of these 462 index trajectories I was unable to find a model that passed the selection criterion.

Selected examples of the AIC-selected dynamics are shown in Fig. 5 and 6, with all the AIC-selected mod- 


\begin{tabular}{|c|c|c|c|c|c|c|c|c|c|c|c|}
\hline & $u$ & $h_{\dot{r} \uparrow}$ & $h_{\dot{r} \downarrow}$ & $s$ & $\zeta_{s}$ & $\zeta_{m}$ & $\zeta_{w}$ & $\zeta_{n}$ & $n^{*} \rightarrow$ & $n^{*} \uparrow$ & $n^{*} \downarrow$ \\
\hline$n$ & - & 16 & 50 & 248 & 9 & 95 & 75 & 69 & 60 & 99 & 89 \\
\hline$\gamma$ & $10^{-2}$ & - & - & $25_{.001}^{220}$ & $83_{15}^{230}$ & $30_{3.4}^{200}$ & $33_{3}^{250}$ & $4.3_{.001}^{150}$ & $11_{.001}^{83}$ & $32^{220} .001$ & $32_{.001}^{250}$ \\
\hline$\gamma_{\iota}$ & $10^{-2}$ & $.39_{.12}^{5.8}$ & $-.63_{-15}^{-.13}$ & $35_{2}^{260}$ & $24_{.001}^{180}$ & $16_{1.4}^{220}$ & $70_{4.5}^{290}$ & $42_{2.4}^{240}$ & $5.5_{.55}^{54}$ & $52_{7}^{290}$ & $48_{4.2}^{250}$ \\
\hline$\gamma_{\iota} \sim \gamma$ & - & - & - & $.73_{1.02}^{.22}$ & $.94_{.91}^{-.35}$ & $.94_{1.24}^{-.12}$ & $.80_{1.15}^{34}$ & .58 .45 & $.88_{.76}^{-.01}$ & $.73_{1.11}^{32}$ & .71 .32 \\
\hline$s\left(a_{m}\right)$ & - & 0 & 0 & 0.42 & 0.44 & 0.52 & 0.44 & 0.25 & 0.48 & 0.44 & 0.34 \\
\hline$\dot{r}$ & $10^{-2}$ & $.39^{5.8}$ & $-.63_{-15}^{-.13}$ & $.00017_{-3.3}^{4.2}$ & $-.31_{-3.2}^{34}$ & $.066_{-2.1}^{5}$ & $-.04_{-3.7}^{3.5}$ & $.0019_{-5.2}^{3.6}$ & $.077_{-3.2}^{8.7}$ & $-.099_{-4.8}^{3.5}$ & $.19_{-2.8}^{4.2}$ \\
\hline$\dot{r}_{l}$ & $10^{-2}$ & $.39_{.12}^{5.8}$ & $-.63_{-15}^{-.13}$ & $-5.2_{-52}^{-.36}$ & $-6.3_{-24}^{1.5}$ & $-3.2_{-59}^{-.24}$ & $-9.9_{-65}^{-.63}$ & $-5.2_{-48}^{-.67}$ & $-1.4_{-15}^{-.17}$ & $-8.1_{-65}^{-1.3}$ & $-6.4_{-52}^{-1.1}$ \\
\hline$\dot{r}_{u}$ & $10^{-2}$ & $.39_{.12}^{5.8}$ & $-.63_{-15}^{-.13}$ & $5.7_{.046}^{60}$ & $1.3_{-.03}^{110}$ & $3.6_{-.032}^{60}$ & $9.5_{.78}^{60}$ & $6.5_{.54}^{51}$ & $1.7_{-.079}^{49}$ & $7.4_{.54}^{47}$ & $8_{1}^{69}$ \\
\hline$n_{\dot{r} \uparrow \downarrow}$ & - & $0_{0}^{0}$ & $0_{0}^{0}$ & $\begin{array}{l}4_{.88}^{15} \\
\end{array}$ & $2_{0}^{4}$ & $3_{0}^{10}$ & $6_{1}^{35}$ & $4_{1}^{15}$ & $2_{0}^{3}$ & $6_{2}^{18}$ & $5_{2}^{13}$ \\
\hline$\Delta r_{s}$ & - & $.071_{.029}^{.34}$ & $.098_{.032}^{1.1}$ & $.21_{.057}^{1}$ & $.27_{1.8 e-5}^{1.6}$ & $.21_{.069}^{.93}$ & $.24_{.057}^{1}$ & $.17_{.051}^{1.5}$ & .14 .93 & $\begin{array}{l}.23 .89 \\
.06\end{array}$ & $.25_{.069}^{1.4}$ \\
\hline$\Delta \tilde{r}_{s}$ & - & $1_{1}^{1}$ & $1_{1}^{1}$ & $1_{.6}^{1.9}$ & $.65^{2.7} .00012$ & $1.1_{.6}^{2}$ & $1_{.67}^{1.4}$ & $1_{.97}^{1.3}$ & $1_{.59}^{2}$ & $1_{.6}^{1.7}$ & $1_{.61}^{1.9}$ \\
\hline$\Delta \tilde{r}_{s / r}$ & - & $1_{1}^{1}$ & $1_{1}^{1}$ & $.67_{.38}^{1}$ & $.42_{.00012}^{56}$ & .6 .78 & .71 .96 & $.92_{.53}^{1}$ & $.65_{.39}^{1}$ & $.69_{.36}^{1}$ & $.67_{.4}^{1}$ \\
\hline$r$ & $10^{-2}$ & $1.1_{-10}^{38}$ & $1.5_{-7.3}^{20}$ & $-.088_{-6.5}^{5}$ & $-2.9_{-9.9}^{5.4}$ & $.14_{-6.5}^{4.9}$ & $-.15_{-5.4}^{4.5}$ & $-.088_{-10}^{6.4}$ & $.43_{-6.5}^{4.9}$ & $1_{-1.4}^{6.4}$ & $-1.9_{-11}^{.013}$ \\
\hline$r_{\min }$ & $10^{-2}$ & $-3_{-26}^{31}$ & $-4.2_{-28}^{9.2}$ & $-9.6_{-68}^{-1.7}$ & $-13_{-94}^{.5}$ & $-8.9_{-44}^{-1.8}$ & $-10_{-86}^{-3}$ & $-8.9_{-68}^{-.84}$ & $-5.3_{-28}^{-1.6}$ & $-9.5_{-44}^{-.84}$ & $-13_{-90}^{-4.2}$ \\
\hline$r_{\max }$ & $10^{-2}$ & $5.3_{-2.7}^{47}$ & $8.6_{-.7}^{57}$ & $9.5_{1.7}^{44}$ & $8_{-1.1}^{47}$ & $9.3_{1.3}^{45}$ & $11_{2.3}^{42}$ & $8_{1.7}^{44}$ & $7.4_{2.3}^{29}$ & $12_{3.8}^{42}$ & 8.1 .78 \\
\hline$n_{r_{\max }}$ & - & - & - & $.97_{.61}^{1.3}$ & $.94_{.56}^{2}$ & $.99^{1.6} 6$ & $.97_{.79}^{1.2}$ & $1_{.75}^{1.1}$ & $.95_{.46}^{2}$ & $.97_{.76}^{1.2}$ & $.97_{.63}^{1.2}$ \\
\hline$n_{r_{\text {min }}}$ & - & - & - & $1_{.6}^{1.8}$ & $1.2^{1.99}$ & $1.1_{.59}^{1.8}$ & $1_{.8}^{1.9}$ & $\begin{array}{r}.99_{.76}^{1.3} \\
\end{array}$ & $1.1_{.5}^{1.9}$ & $\begin{array}{l}1.9 \\
.85 \\
\end{array}$ & $\begin{array}{l}1.5 \\
1.65 \\
\end{array}$ \\
\hline$\hat{n}$ & - & - & - & $1.3_{1.1}^{2.7}$ & $1.4_{1}^{2.1}$ & $1.4_{1.1}^{3.3}$ & $1.2_{1.1}^{1.9}$ & $1.2_{1.1}^{2}$ & $1.5_{1.1}^{6.4}$ & $1.2_{1.1}^{2}$ & $1.2_{1.1}^{2.3}$ \\
\hline$T$ & $y$ & - & - & $25_{4.6}^{150}$ & $68_{0}^{1100}$ & $38_{10}^{140}$ & $17_{1.7}^{75}$ & $25_{1.3}^{86}$ & $61_{31}^{230}$ & $19_{5.7}^{43}$ & $21_{1.3}^{67}$ \\
\hline
\end{tabular}

Table 1: Dynamics. Estimates of key parameters and population responses for the AIC-selected models with hyperexponential acceleration $\left(h_{\dot{r} \uparrow}\right)$, hyper-exponential deceleration $\left(h_{\dot{r} \downarrow}\right)$, all selection-regulated models $(s)$, and those with strongly $\left(\zeta_{s}\right)$, medium $\left(\zeta_{m}\right)$, weak $\left(\zeta_{w}\right)$, and negatively $\left(\zeta_{n}\right)$ damped dynamics, and those with stable $\left(n^{*} \rightarrow\right)$, increasing $\left(n^{*} \uparrow\right)$, or declining $\left(n^{*} \downarrow\right)$ population dynamic equilibria. u:unit, $n$ :nr. of models, and $x_{b}^{a}$ lists median $(x), 97.5 \%(a)$ and $2.5 \%(b)$ quantiles of model distributions for $\gamma$ :density regulation; $\gamma_{\iota}$ :selection regulation; $\gamma_{\iota} \sim \gamma$ :correlation coefficient $(x)$ and intercept $(a)$ and slope $(b)$ of linear regression $\gamma=a+b \gamma_{\iota} ; s\left(a_{m}\right)$ :fraction with regulation also in $a_{m} ; \dot{r}$ :average growth rate acceleration per trajectory; $\dot{r}_{l}: 2.5 \% \dot{r}$-quantile; $\dot{r}_{u}: 97.5 \% \dot{r}$-quantile; $n_{\dot{r} \uparrow \downarrow}: \mathrm{nr}$. of shifts in direction of selection per trajectory; $\Delta r_{s}$ :accumulated selection regulation per trajectory (eqn 24); $\Delta \tilde{r}_{s}: \Delta r_{s}$ divided by span in growth rate (eqn 26); $\Delta \tilde{r}_{s / r}: \Delta r_{s}$ divided by total accumulated regulation (eqn 25); $r$ :average growth rate per trajectory; $r_{\min }:$ minimum growth rate; $r_{\max }:$ maximum growth rate; $n_{r_{\min }}: n / n^{*}$ at $r_{\min } ; n_{r_{\max }}: n / n^{*}$ at $r_{\max } ; \hat{n}$ :maximum cycle amplitude $\left(n_{\max } / n^{*}\right.$ or $\left.n^{*} / n_{\min }\right) ; T$ :period of population cycle.

els that explain more than $50 \%$ of variance plotted in Supplement S4.

For the 335 index trajectories where a satisfactory model was found, selection-based models were preferred in $94 \%$ of the cases, with the selection-based models being 25, 000 (95\%:0.42-1.7e17) times more probable than population dynamic models with no selection included (based on relative AIC). Among the final selection of models, selection-regulated dynamics were preferred in $74 \%$ of the cases, followed by $20 \%$ hyper-exponential models, $3.9 \%$ exponential models, and $2.4 \%$ densityregulated models. The fractions of the variance in the index trajectories that were explained by the final models were $0.82(95 \%: 0.51-0.98)$.
Table 1 list population dynamic information across the selected models, excluding the 13 exponential and 8 density-regulated models. With

$$
\Delta r_{d}=\gamma \ln \left(n_{\max } / n_{\min }\right)
$$

being the accumulated density regulation (i.e., the span of the growth rate explained by density regulation, with $n_{\min }$ and $n_{\max }$ being the minimum and maximum abundance of a trajectory), and

$$
\Delta r_{s}=\ln \left(q_{\max } / q_{\min }\right)
$$

being the acculumated selection regulation (with $q_{\text {min }}$ and $q_{\max }$ being the minimum and maximum of the average competitive quality of mature individuals), we 
may estimate the relative accumulated selection regulation, i.e., the fraction of the overall regulation that is explained by natural selection as

$$
\Delta \tilde{r}_{s / r}=\Delta r_{s} / \Delta r_{r}
$$

where $\Delta r_{r}=\Delta r_{s}+\Delta r_{d}$. The accumulated selection regulation may also be expressed relative to the overall span in the realised growth rate

$$
\Delta \tilde{r}_{s}=\Delta r_{s} / \Delta r
$$

where $\Delta r=r_{\max }-r_{\min }$.

For the 248 AIC-selected selection-regulated models the relative accumulated selection regulation $\left(\Delta \tilde{r}_{s / r}\right)$ was estimated to 0.67 (95\%:0.38-1). Natural selection is thus a more important regulating factor than density regulation. Selection regulation is equal in magnitude to the total span in realised growth, with the estimate of $\Delta \tilde{r}_{s}$ being 1 (95\%:0.6-1.9).

The high importance of regulation by natural selection is apparent in the dynamics, which is quite different from density-regulated growth. Excluding extremely strong density regulation, density-regulated growth is fully damped with a damping ratio of unity. But the estimated damping ratios for North American birds are only 0.15 (95\%:-0.19-1), which is rather close to stable cycles (distribution shown in Fig. 4). The estimated maximal amplitudes relative to the equilibrium abundance were $1.3(95 \%: 1.1-2.7)$, with the estimated cycle periods being $26 \mathrm{y}$ (95\%:5.3y-150y).

Based on the concepts of exploitation and density regulation it is widely assumed that populations increase at a maximal per capita growth rate $\left(r_{\max }\right)$ when they are at low densities where there are plenty of resources. The BBS data do not support this assumption. Given the AIC-selected models, North American birds were found to increase at maximum per capita rates, and decline at minimum per capita rates, in the vicinity of the population dynamic equilibrium, with the estimated relative abundance $\left(n / n^{*}\right)$ at $r_{\max }$ and $r_{\text {min }}$ being 0.97 (95\%:0.61-1.3) and 1 (95\%:0.6-1.8).

The concept that the growth rate is set as a function of the environment is also not supported. This implies a single well defined growth rate at a given abundance, which is in conflict with the multitude of trajectories with not just uneven growth rates, but also opposite growth directions, at similar densities at different times. A pattern with opposite growth at similar densities follows from growth rate acceleration/deceleration by population dynamic feedback selection.

\begin{tabular}{l|rrrrr} 
& BBS & BTO & DOF & GPDD & All \\
\hline \hline$n$ & 462 & 111 & 215 & 420 & 1208 \\
$n_{m}$ & 335 & 77 & 99 & 230 & 741 \\
\hline$s$ & $94 \%$ & $84 \%$ & $65 \%$ & $87 \%$ & $87 \%$ \\
$\tilde{p}$ & $1_{-.57}^{1}$ & $.99_{-.63}^{1}$ & $.92_{-.83}^{1}$ & $1_{-.77}^{1}$ & $1_{-.63}^{1}$ \\
$\sigma^{2}$ & $.82_{.51}^{.98}$ & $.81_{.53}^{.99}$ & $.73_{.51}^{96}$ & $.75_{.51}^{.98}$ & $.78_{.51}^{.98}$ \\
$\Delta \tilde{r}_{s / r}$ & $.75_{.39}^{1}$ & $.73_{.35}^{1}$ & $.71_{.33}^{1}$ & $.76_{.34}^{1}$ & $.75_{.35}^{1}$ \\
$\zeta$ & $.15_{-.19}^{.89}$ & $.11_{-.22}^{.97}$ & $.2_{-.096}^{.89}$ & $.042_{-.36}^{.86}$ & $.12_{-.24}^{.9}$ \\
$T$ & $26_{5.3}^{150}$ & $14_{5.3}^{100}$ & $26_{1.7}^{97}$ & $19_{3.1}^{110}$ & $22_{4.3}^{120}$ \\
\hline
\end{tabular}

Table 2: Different data sets. Population dynamic estimates for North American (BBS, Sauer et al., 2017), British (BTO, 2020), and Danish (DOF, 2020) birds, and the GPDD (2010). $n$ :nr. of trajectories, $n_{m}$ :nr. of accepted models, $s$ :percentage of accepted models with selection, and $x_{b}^{a}$ listing median $(x), 97.5 \%(a)$ and $2.5 \%(b)$ quantiles of model distributions for $\tilde{p}$ :the probability of selection model relative to nonselection model (eqn 22); $\sigma^{2}$ :explained variance; $\Delta \tilde{r}_{s / r}$ :fraction of total regulation explained by selection (eqn 25); $\zeta$ :damping ratio; $T$ :population period in years.

\subsection{BTO, DOF, \& GPDD}

Table 2 shows that the major population dynamic findings for the BBS are found also among British birds, Danish birds, and the birds and mammals in the Global Population Dynamic Database. $78 \%$ of the variance in the population trajectories are explained on average across 741 populations with accepted models, with $87 \%$ of these having a selection acceleration/deceleration of the growth rate, with the relative probability of the selection models (from eqn 22) being 1 (95\%:-0.631 ). Among the final selection of models there are only 4.5\% density-regulated models, with the fraction of the growth rate regulation that is explained by selection being 0.75 (95\%:0.35-1), and the damping ratios of the dynamics being 0.12 (95\%:-0.24-0.9). 
bioRxiv preprint doi: https://doi.org/10.1101/2021.11.27.470201; this version posted November 27, 2021. The copyright holder for this preprint (which was not certified by peer review) is the author/funder, who has granted bioRxiv a license to display the preprint in perpetuity. It is made available under aCC-BY-NC-ND 4.0 International license.
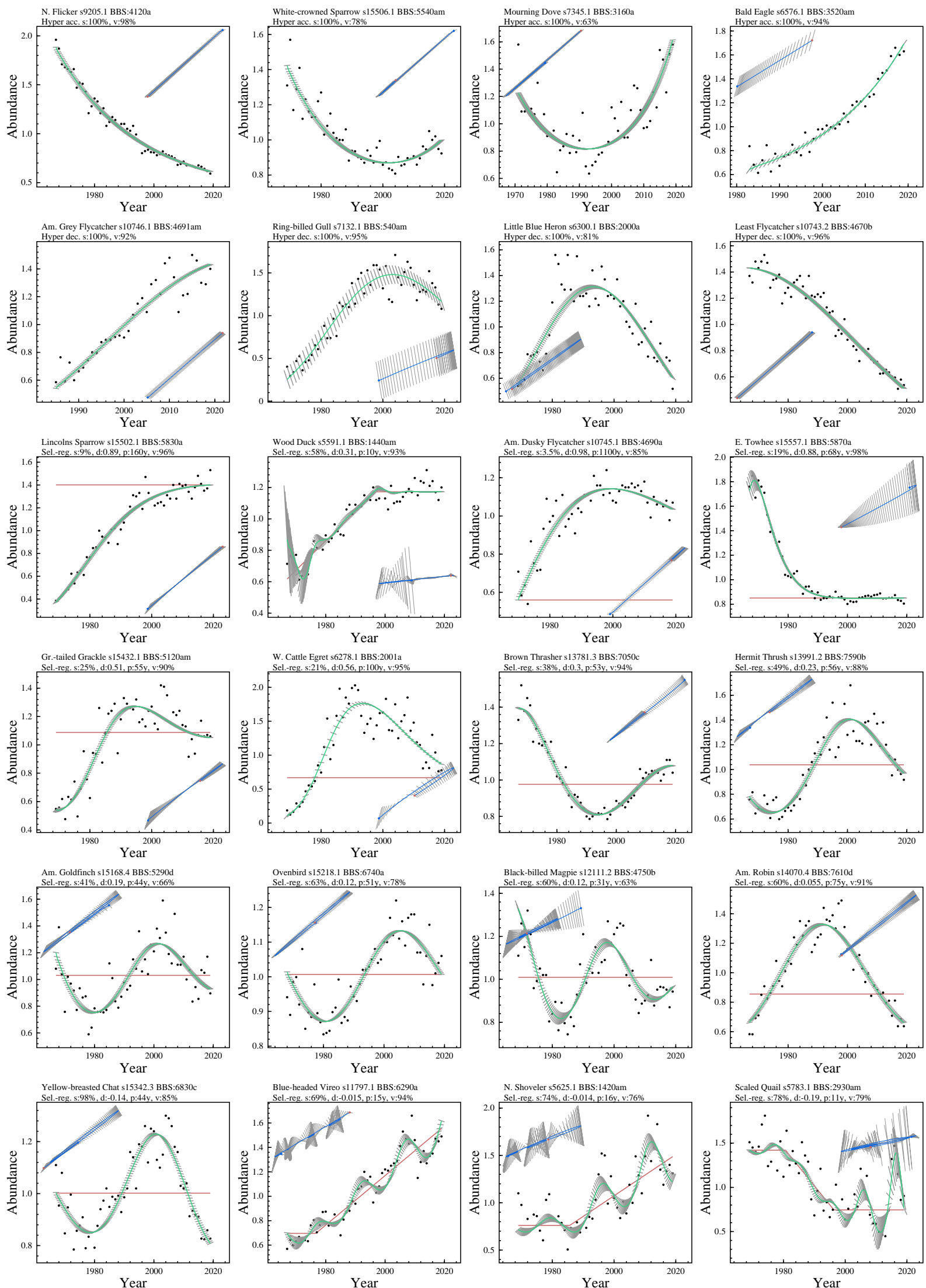

Figure 5: Selection dynamics. Population trajectories of North American birds showing hyper-exponential acceleration (1. row), hyper-exponential deceleration (2. row), an almost monotonic return to equilibrium (selection-regulated with $\zeta \geq 0.8$, 3. row), damped cyclic dynamics $(0.2 \leq \zeta<0.8,4$. row $)$, about stable cyclic $(0 \leq \zeta<0.2$, 5 . row $)$, and exploding cyclic $(\zeta<0,6$. row). Dots are the BBS index series, red lines the estimated equilibria, green curves the model trajectories, blue curves scaled $n_{t+1}-n_{t}$ plots (running from blue to red dot), and grey lines being the intra-population selection gradients that cause the acceleration and deceleration of the growth rate. 
bioRxiv preprint doi: https://doi.org/10.1101/2021.11.27.470201; this version posted November 27, 2021. The copyright holder for this

preprint (which was not certified by peer review) is the author/funder, who has granted bioRxiv a license to display the preprint in perpetuity. It is made available under aCC-BY-NC-ND 4.0 International license.

L. Witting: Selection-regulated population dynamics
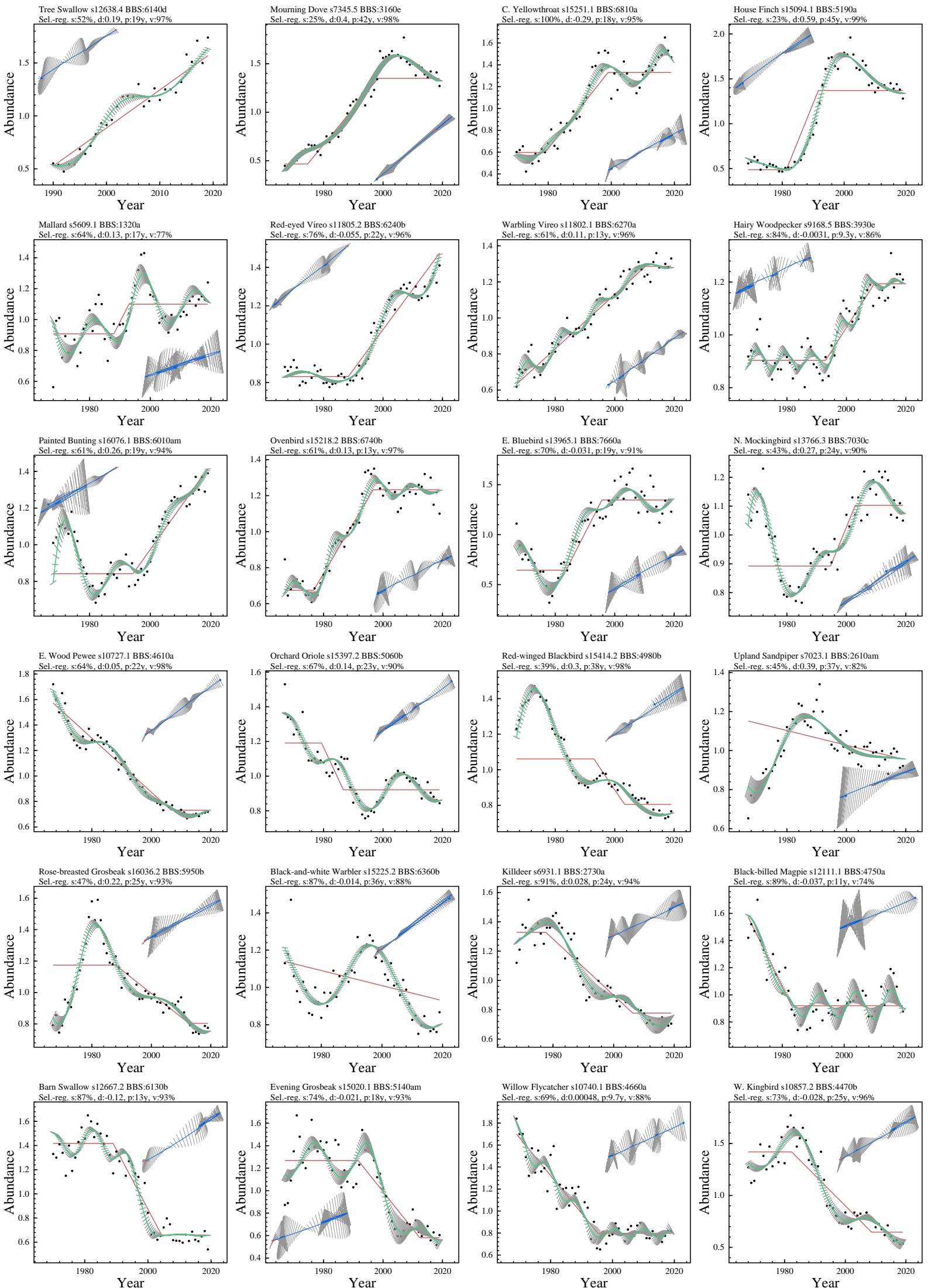

Figure 6: Changing equilibria. Population trajectories of North American birds for selection-regulated models with an increase (first half of plots) and decrease (second half) in the population dynamic equilibrium. Dots are the BBS index series, red lines the estimated equilibria, green curves the model trajectories, blue curves scaled $n_{t+1}-n_{t}$ plots (running from blue to red dot), and grey lines being the intra-population selection gradients that cause the acceleration and deceleration of the growth rate. 


\subsection{Selection dynamics in the BBS}

Selection induced growth rate acceleration/deceleration is essential in $94 \%$ of the best AIC-selected models for North American birds. The form and strength of the selection differ across populations, with the dynamics of North American birds falling in nine categories described below and listed in Table 1 . The geographical distribution of the population dynamics across six ecotypes of North American birds are described in Appendix B.

Hyper-exponential acceleration $\left(h_{\dot{r} \uparrow}\right)$. Population trajectories with a constantly accelerating growth rate were estimated as the best model for 16 populations of North American birds. While we do not expect the long-term dynamics of any bird population to be truly hyper-exponential, the hyper-exponential model appears to be a fair approximation in cases where we are unable to identify a change in the acceleration of the growth rate over the time-period of a study.

Four examples of hyper-exponential acceleration in the top row of Fig. 5 illustrate that some populations have a continuously declining trajectory, while others have a continuously increasing trajectory. The majority of the accelerating hyper-exponential trajectories in North American birds, however, are first declining and then stabilising before an increase. The latter are typical examples of evolutionary rescue, where the initial decline would continue until the population became extinct was it not for the selection-induced acceleration of the growth rate.

The estimates of the selection parameter $\left(\gamma_{\iota}\right)$ for the hyper-exponential models are about two orders of magnitude smaller than the estimates for the selectionregulated models. Yet, the absolute estimates for the median per-generation acceleration of the growth rate $(\dot{r})$ are about two orders of magnitude larger for the hyper-exponential models. This reflects the distributions with both accelerating and decelerating growth in the selection-regulated models, while models of hyperexponential acceleration refer to populations below the population dynamic equilibrium. If we look at the lower and upper quantiles for the intra-trajectory variation in the growth rate acceleration of the selection-regulated models, we find these quantiles to be about an order of magnitude larger in the selection-regulated models, reflecting strong selection far from equilibrium.

Hyper-exponential deceleration $\left(h_{\dot{r} \downarrow}\right)$. Population trajectories with a constantly decelerating growth rate were estimated for 50 populations. The second row of Fig. 5 illustrates that some of these have a continuously increasing trajectory, while others are continuously declining, although the majority of the decelerating hyper-exponential trajectories are first increasing and then stabilising before a decline. The latter are typical examples of populations that are over-shooting their equilibria, with an apparently rather constant level of interactive competition selecting for a steady increase in interactive quality and a corresponding decline in the growth rate.

Strongly damped dynamics $\left(\zeta_{s}=\zeta \geq 0.8\right)$. About $4 \%$ of the selection-regulated models have strongly damped $(\zeta \geq 0.8)$ dynamics that behave somewhat like a monotonic return to equilibrium, with examples shown in Fig. 5 (third row). Over the 54 year period of the BBS, each of these populations have almost unidirectional selection, with the estimated number of changes in the direction of selection being 2 (95\%:04 ), compared with 4 (95\%:0.88-15) for the selectionregulated models in general. The strong damping implies that the underlying cycles are long with estimates periods of $68 \mathrm{y}$ (95\%:0y-1,100y).

It is when density regulation is strong relative to selection regulation (large $\gamma / \gamma_{\iota}$-ratios) that selection-regulated dynamics approaches densityregulated growth with damping ratios around unity. With $\gamma$ estimates of 0.83 (95\%:0.15-2.3) the strengths of density regulation in the $\zeta_{s}$ models are approximately three times stronger than in the selectionregulated models in general, where $\gamma$ estimates are 0.25 (95\%:1e - 5-2.2). The estimated strength of selection regulation $\gamma_{\iota}=0.24(95 \%: 1 \mathrm{e}-5--1.8)$ is only somewhat weaker than for the selection-regulated models in general, where it is 0.35 (95\%:0.02-2.6).

Even though the estimated force of selection is relatively weak in populations with strongly damped dynamics, the accumulated selection induced changes in the growth rate $\Delta r_{s}=0.27(95 \%: 1.8 e-5-1.6)$ are generally similar or slightly larger than for the selectionregulated models in general, where the estimates are 0.21 (95\%:0.057-1). The reason for this is the fewer changes in the direction of selection allowing for longer periods to accumulate growth rate accelerations, or decelerations.

When the selection induced changes in the growth rate is measured against total growth rate regulation, we find that the strongly damped dynamics have the smallest relative influence from selection with $\Delta \tilde{r}_{s / r}$ estimates of $0.42(95 \%: 0.00012-0.56)$. Yet, with $\Delta \tilde{r}_{s}$ estimates of 0.65 (95\%:0.00012-2.7) the selection induced changes are generally accounting for more than 
half of the difference between the maximum and minimum growth rates.

Medium damped dynamics $\left(\zeta_{m}=0.2 \leq \zeta<0.8\right)$. A medium damping ratio between 0.2 and 0.8 was estimated for $38 \%$ of the selection-regulated models. As shown in the fourth row of Fig. 5, this generates damped cycles that over- or under-shoots the equilibrium and converges towards it within a single or a few cycles. The estimated cycle periods of $38 \mathrm{y}$ (95\%:10y-140y) are only slightly longer than the estimates of $25 \mathrm{y}$ (95\%:4.6y$150 \mathrm{y})$ across all selection-regulated models. The estimated shifts in the direction of selection [3 (95\%:0-10)] are generally one less than for the selection-regulated models in general.

The estimated $\gamma / \gamma_{\iota}$-ratios of $1.5(95 \%: 0.56-7.8)$ are somewhat larger than unity, while estimates of 0.66 (95\%:3.3e - 5-6.7) in the selection-regulated models in general are somewhat lower. This implies a strength of density regulation that is about 1.5 times stronger than selection regulation, however, owing to the different ways of action on $r$ and $\dot{r}$ the accumulated selection regulation is 0.6 (95\%:0.39-0.78) times total regulation by density and selection. And with $\Delta \tilde{r}_{s}$ estimates of 1.1 (95\%:0.6-2) this implies selection induced changes that are equal in magnitude to the difference between the maximum and minimum growth rate.

Stable population cycles $\left(\zeta_{w}=0 \leq \zeta<0.2\right)$. A majority $(58 \%)$ of the selection-regulated models have weak damping ratios below 0.2 , with $30 \%$ of the ratios being larger than zero. As shown in the second last row of Fig. 5, this dynamics is cyclic with almost stable cycles, with $6(95 \%: 1-35)$ shifts in the direction of selection over the fifty-year period of the data, and cycle periods of $17 \mathrm{y}(95 \%: 1.7 \mathrm{y}-75 \mathrm{y})$.

The strength of selection regulation is notably larger than the strength of density regulation, with an estimated $\gamma_{\iota} / \gamma$-ratio of $1.8 \quad(95 \%: 0.71-6.6)$. Yet, the estimated strength of density regulation $[\gamma=0.33$ (95\%:0.03-2.5)] is about the same, or somewhat larger, than for the selection-regulated models in general, where it is $0.25(95 \%: 1 e-5-2.2)$. The increased relative importance of selection regulation reflects an increased strength/response to selection, with $\gamma_{\iota}$ being 0.7 (95\%:0.045-2.9) relative to 0.35 (95\%:0.02-2.6) for the selection-regulated models in general.

The increased importance of selection is apparent in the accumulated changes in the growth rate, where a 0.71 (95\%:0.36-0.9) fraction of total regulation by density and selection is caused by population dynamic feedback selection.
Exploding selection-dynamics $\left(\zeta_{n}=\zeta<0\right)$. Selection-regulated dynamics is unstable with increasing amplitudes in exploding cycles when the damping ratio is negative. This special type of dynamics was estimated for $28 \%$ of the selection-regulated models. It is somewhat unexpected to observe populations with exploding cycles as these are likely to go extinct unless the instability is transient.

A large fraction of the populations with point estimate of $\zeta$ below zero have upper confidence limits above zero. Yet, when these are removed there are still 29 remaining populations where the estimated damping ratios are significantly smaller than zero. At least for a few of these, like the two to the right in the last row of Fig. 5, the cyclic dynamics is indeed looking unstable with amplitudes that increase over time. The estimated periods for exploding cycles [25y (95\%:1.3y-86y)] are about similar to that of the selection-regulated models in general, and so are the number of shifts in the direction of selection [4 (95\%:1-15)].

The increase in the relative importance of selection from the strongly damped dynamics $(\zeta>0.8)$ to the stable $(0<\zeta<0.2)$ population cycles was caused primarily by an increase in the strength/response to selection. Yet, the stronger relative influence of selection in the exploding dynamics, where the $\gamma_{\iota} / \gamma$-ratio is estimated to 6.6 (95\%:0.94-64,000), is caused primarily by a density regulation ( $\gamma$ estimates of 0.043 (95\%:1e - 5$1.5)$ ) that is an order of magnitude weaker than for the selection-regulated models in general . In consequence, the accumulated regulation of the growth rate by selection is 0.92 (95\%:0.53-1) of total regulation.

The estimated maximal amplitudes of the exploding cycles $\hat{n}=1.2(95 \%: 1.1-2)$ are similar to that of the selection-regulated models in general, where the estimates are 1.3 (95\%:1.1-2.7). This implies that none of the observed unstable cycles have exploded to extreme densities. The estimated instability might reflect nothing more than a lack of statistical detection of density regulation. If not, it does not exclude the action of density regulation at more extreme densities, with an associated stabilisation of the dynamics.

Increasing \& decreasing equilibria. A change in equilibrium abundance over time was estimated in $76 \%$ of the selection-regulated models, with an increase in equilibrium estimated for 99 populations, and a decline for 89 . The estimated proportional magnitude $\left(n_{\max }^{*} / n_{\min }^{*}\right)$ of the changes were about similar for populations with an increasing $[1.6(95 \%: 1.1-2.9)]$ and declining equilibria $[1.4(95 \%: 1.1-2.8)]$, and so were the durations of the changes taking $25 \mathrm{y}(95 \%: 5.7 \mathrm{y}-53 \mathrm{y})$ for 
bioRxiv preprint doi: https://doi.org/10.1101/2021.11.27.470201; this version posted November 27, 2021. The copyright holder for this

\begin{tabular}{c|ccc} 
& $n^{*} \rightarrow$ & $n^{* \uparrow}$ & $n^{*} \downarrow$ \\
\hline$\zeta_{s}$ & 0.05 & 0.02 & 0.04 \\
$\zeta_{m}$ & 0.65 & 0.29 & 0.30 \\
$\zeta_{w}$ & 0.12 & 0.38 & 0.34 \\
$\zeta_{n}$ & 0.18 & 0.30 & 0.31 \\
\hline \hline
\end{tabular}

Table 3: Damping vs. trend. The fractions of the four damping ratio categories in the subsets of selectionregulated models with a stable, increasing, or decreasing equilibrium abundance.

the increasing, and 19y (95\%:5.5y-52y) for the declining, equilibria.

The relative strength of selection regulation is rather strong and about similar for populations with increasing or decreasing equilibria [with $\gamma_{\iota} / \gamma$ estimates of 2 (95\%:0.32-31,000) and 1.6 (95\%:0.28-32,000)], and so are the absolute strength [with $\gamma_{\iota}$ estimates of 0.52 (95\%:0.07-2.9) and 0.48 (95\%:0.042-2.5)]. The relative strengths of selection regulation are weaker among populations with a stable equilibria $\left[\gamma_{\iota} / \gamma=0.59\right.$ (95\%:0.061-11,000)] and so are the absolute strengths $\left[\gamma_{\iota}=0.055(95 \%: 0.0055-0.54)\right]$.

These differences reflect stronger growth rate accelerations in populations with changing equilibria, with the medians for the lower and upper quantiles of $\dot{r}$ being -0.081 and 0.074 for increasing, and -0.064 and 0.08 for declining, equilibria compared with -0.014 and 0.017 for stable equilibria. Yet, the accumulated selection-changes in the growth rates $\left(\Delta r_{s}\right)$ are about the same in all three cases, and so are the accumulated relative selection regulations $\left(\Delta \tilde{r}_{s / r}\right)$.

The stronger growth rate accelerations generate faster cycles with periods of $20 \mathrm{y}(95 \%: 1.7 \mathrm{y}-63 \mathrm{y})$ for populations with changing equilibria, relative to $61 \mathrm{y}$ $(95 \%: 31 y-230 y)$ for stable equilibria. This leads to more changes in the direction of selection [5 (95\%:2$17)$ vs. $2(95 \%: 0-3)]$, and to relatively similar accumulated changes despite of the stronger selection. In many cases, as shown in Fig. 6, this generates short population cycles that track the increasing or declining equilibrium. In all cases - with stable or changing equilibria - the realised growth rates are taking their maximum and minimum values when the trajectories cross the stable or moving equilibrium abundance.

Table 3 list the fractions of the four damping ratio categories in the subsets of selection-regulated models with a stable, an increasing, or decreasing equilibrium abundance. The medium $\left(\zeta_{m}\right)$ damped dynamics is overrepresented among populations with stable equilibria, while the weakly $\left(\zeta_{w}\right)$ and negatively $\left(\zeta_{n}\right)$ damped dynamics with stable to exploding cycles are overrepresented among populations with increasing or declining equilibria.

\section{Discussion}

The essence of traditional population ecology is population dynamic growth rates that are density-regulated downwards from optimal values. This fundament, however, has been challenged by evidence for decades. The green world paradox (Hairston et al. 1960) identified the problem: Why are the resources of natural populations abundant, when they are predicted to be so scarce that the average individual cannot find sufficient resources for optimal reproduction and survival?

Another problem is widespread population cycles that are inconceivable with density-regulated growth on non-cyclic resources. For a century or so, population cycles were seen to follow from density-dependent interactions between predators and prey. There is, however, a suspicious lack of studies that quantify the necessary interactions, and plenty of evidence hinting at other mechanisms for cyclic dynamics. Studying an isolated Daphnia-algae system, Murdoch and McCauley (1985) found Daphnia to cycle with a relatively fixed period independently of the presence versus absence of a cycle in its prey. Other hints included snowshoe hares that cycle in the absence of lynx (Keith 1963), a best documented cycle in forest insects that lacks a firm predatorprey interaction (Berryman 1996), removal experiments where prey continue to cycle when predators are removed (Krebs 1996; Oli 2003a,b), and similar experiments concluding that predator-prey interactions are unable to explain the observed cycles (Graham and Lambin 2002).

The failure to identify the necessary population dynamic interactions invoked group-selection arguments where the exploitation balance and population cycles were obtained by individuals that scarified their own fitness for the benefit of the population (Chitty 1960; Wynne-Edwards 1962, 1986, 1993). Another apparent explanation was delayed density-dependent models that did not explicitly incorporate the essential food-web interactions (e.g., Hutchinson 1948; Witteman et al. 1990; Turchin and Taylor 1992; Hörnfeldt 1994; Hansen et al. 1999a,b; Stenseth et al. 2003). While the latter studies did model much of the dynamics, they turned the blind eye to the real problem; the lack of ability to identify and model the necessary interactions behind the delayed regulation. 
Ginzburg (1972, 1998) argued for a change of concept; moving from explaining the growth rate, to explaining only the acceleration of the growth rate. And with the development of population dynamic feedback selection from the density-dependent interactive competition within the population, Witting (1997, 2000a,b, 2002) deduced the acceleration hypothesis from selection regulation; a new and alterative mechanism to density regulation.

\subsection{Selection regulation evidence}

Selection regulation proved successful by predicting the cyclic dynamics of forest insects (Witting 1997, 2000b), as well as the delayed recovery of large whales following commercial exploitation in past centuries (Witting 2003, 2013). Other evidence include profound genetic changes over few generations in cyclic populations (Semeonoff and Robertson 1968; Krebs et al. 1973; Sinervo et al. 2000). Delayed life history changes in natural populations (Mousseau and Fox 1998; Beckerman et al. 2002). Heritable differences in the birth rate between individuals from the low and increasing phase of a cycle (Mihok and Boonstra 1992). And an acceleration of the population dynamic growth rate by up to $40 \%$ within few generations (Turcotte et al. 2011a,b).

Selection by density-dependent competitive interactions generates a two-generation cycle in the abundance and competitive quality of side-blotched lizard (Uta stansburiana; Sinervo et al. 2000), and the abundance cycle in the Daphnia experiments of Murdoch and McCauley (1985) had an associated cycle in body mass, with the larger Daphnia occurring mainly in the late peak phase of the cycle and the smaller mainly in the early increasing phase (Witting 2000a). Similar changes in body mass are widespread in voles and lemmings with cyclic dynamics (Chitty 1952; Hansson 1969; Krebs and Myers 1974; Boonstra and Krebs 1979; Mihok et al. 1985; Lidicker and Ostfeld 1991; Stenseth and Ims 1993; Ergon et al. 2001; Norrdahl and Korpimäki 2002; Lambin et al. 2006), and they have been observed in snowshoe hare (Hodges et al. 1999), cyclic forest insects (Myers 1990; Simchuk et al. 1999), and the highly depleted population of North Atlantic right whales (Stewart et al. 2021).

Cycles in other traits have been reported by Naumov et al. (1969) who found that the percentage of males increased in small rodents when densities are high, while females predominate during the low phase. Other cases of an increased male fraction with increased density include white-tailed deer (Odocoileus virginianus) (McCullough 1979) and northern elephant seal (Mirounga angustirostris) (Le Boeuf and Briggs 1977). And the abundance cycles in red grouse (Lagopus lagopus scotica) are associated with cycles in kin structure, with larger kin groups evolving during the increasing phase of a cycle (Watson et al. 1994; Matthiopoulos et al. 2003; Piertney et al. 2008). All these traits represent different components of competitive quality, with their population dynamic associated cycles, and more general evolution, being predicted by the population dynamic feedback selection of density-dependent interactive competition (Witting 1997, 2008).

While several studies document evolutionary changes in the genetic composition of populations at population dynamic timescales, it is essential to realise that selection induced growth rate accelerations/decelerations are not restricted to genetic responses. In fact, the population response to selection might in some cases be almost entirely driven by non-genetic changes like cultural inheritance. Offspring that balance their quality/quantity investment in their offspring following the balance learned from their parents, is a fully adequate inheritance system for selection regulation to work. The few offspring that choose another balance are the cultural inheritance equivalence of genetic mutations that maintain the heritable variance of the population.

I used the North American Breeding Bird Survey (Sauer et al. 2017) for a large-scale test on the importance of selection regulation relative to density regulation in the dynamics of natural populations. From 6.18 mill. standardised bird observations in the BBS I estimated 462 population dynamic trajectories with yearly abundance estimates for about 50 years each, covering 299 species. Applying maximum likelihood fitting and AIC model selection, I found the selectionregulated models to be 25,000 (95\%:0.42-1.7e17) times more probable than traditional density-regulated models. Selection is essential in $94 \%$ of the AIC-selected models, explaining $82 \%$ of the variance in the abundance trajectories. Selection-regulated dynamics was preferred in $74 \%$ of the cases, followed by $20 \%$ hyperexponential models, $3.9 \%$ exponential models, and $2.4 \%$ density-regulated models.

Selection regulation is 1.5 (95\%:0.15-30,000) times stronger than density regulation across the selectionregulated models, with a 0.75 (95\%:0.39-1) fraction of total regulation explained by selection. Selection regulation is more important than density regulation, and the accumulated selection regulation is similar in magnitude to the difference between the observed maximum and minimum growth rates $\left[\Delta \tilde{r}_{s}=1\right.$ (95\%:0.6-1.9)]. Similar results were obtained across 111 populations of British birds (BTO 2020), 215 populations of Dan- 
ish birds (DOF 2020), and 420 bird and mammal populations in the Global Population Dynamic Database (GPDD 2010).

\subsection{Breeding Bird Survey}

The selection-regulated models identified interesting patterns across the ecotypes and spatial distributions of North American birds (Appendix B). The average growth rate per trajectory was about zero on average across all models. Yet, growth was mainly positive among waterfowl, raptors, and insect eating passerines, and mainly negative among shorebirds, seed eating and ground living passerines. These differences were pronounced over the whole continent, except that shorebirds had predominately positive growth in the central east, and ground living passerines predominately positive growth in the central and far west.

These growth patterns were in part explained by changing equilibrium abundancies. Only $24 \%$ of the best selection-regulated models had a stable equilibrium abundance, while $40 \%$ experienced an increase in equilibrium, and $36 \%$ a decline. Increasing equilibria where mainly found in waterfowl and raptors, with declining equilibria being dominant in shorebirds. Insect eating, seed eating and ground feeding passerines had predominantly increasing equilibria in some areas and declining equilibria in others.

The strength of selection regulation was on average stronger than density regulation in all ecotypes. Density regulation, however, dominated selection regulation in shorebirds in the eastern half of the continent, in ground living passerines in north-west and north-east, and in few scattered areas in the remaining ecotypes.

The patterns of predominantly accelerating or decelerating growth rates were more complex, reflecting the degree to which the different populations were on average below or above their stable, increasing, or declining equilibria. Increasing raptors were mostly below their equilibrium abundancies experiencing accelerating growth, while increasing waterfowl and shorebirds were predominantly above their equilibria (often mainly in the second half of the BBS period) experiencing a deceleration of growth. Three ecotypes of passerines had a more even split between accelerating and decelerating growth.

The accumulated selection regulation over the fiftyyear period of the BBS dominated density regulation in all ecotypes and areas, except for a few scattered areas in waterfowl and shorebirds.

\subsection{A new ecological paradigm}

Both density and selection were found to regulate the dynamics of most species, but traditional densityregulated models with no selection fail to describe the dynamics in most cases.

Models with no selection assume that populations increase at optimal (maximal) per-capita rates when they are at low densities with no competition and plenty of resources. This concept, however, is not supported by the 1,200 population dynamic trajectories that I analysed. Based on the best AIC-selected models, populations were found to increase at their maximum per capita rate, and decline at their minimum per capita rate, in the vicinity of the population dynamic equilibrium. This follows from a selection regulation that accelerates the growth rate below the equilibrium and decelerates the growth rate above.

Density-regulated growth in stable environments with no selection implies that there is a single well defined growth rate for any given abundance. This conflicts with the multitude of populations that have not just uneven growth rates, but also growth in opposite directions, at similar densities at different times. Opposite growth at similar densities follows from growth rate acceleration/deceleration by population dynamic feedback selection.

Another essential assumption relates to the exploitation of natural populations. Density-regulated populations can be exploited with a maximum sustainable yield (MSY) at their maximum sustainable yield level (MSYL). This concept is treated almost as a law of sustainable use, as defined e.g. by Article 61(3) in the United Nations Convention on the Law of the Sea. It states that measures of exploitation shall be designed "to maintain or restore populations of harvested species at levels which can produce the maximum sustainable yield" (UN 1982). But with selection regulation included there are no MSY and MSYL calling for a thorough revision of our theory on sustainable use (see Witting 2002; Holt 2004).

I conclude that the traditional paradigm - where demographic rates are optimal at low population densities, and equilibrium populations are density-regulated to a sub-optimal, or even detrimental, carrying capacity where individuals cannot find sufficient resources for reproduction and/or survival - is a dead end for our ability to understand population ecological processes.

Population ecology is immensely differently structured with selection regulation. It defines population dynamics as transient perturbations in the long-term natural selection of abundance and life histories. These 
long-term attractors are dealt with more easily by models that are continuously situated at the population dynamic equilibrium. The population model in this paper, e.g., is a dynamic version of a model that was used to predict the natural selection of non-negligible sized multicellular and sexually reproducing mobile organisms (Witting 1997, 2008, 2017a,b).

Population dynamic feedback selection implies life histories and demographic rates that are optimised and adapted to the ecological conditions at population dynamic equilibria. And with the selection equilibrium being defined by a competitive resource bias that ourbalances the quality-quantity trade-off, the strict evolutionary equilibrium is a population where all individuals reproduce and survive at the same optimal rates with no population dynamic growth. At equilibrium, the competitively superior individuals obtain more resources than the competitively inferior, but they do also invest more resources in each offspring with the endresult being that both variants have about similar rates of survival and reproduction (Witting 1997).

The equilibrium abundance might impose somewhat depleted resources relative to the case with no exploitation. But the equilibrium resource densities are the ecological conditions experienced by most populations, and thus the ecological conditions towards which their life histories are long-term adapted. Hence, I define density regulation (eqns 7 and 17) and selection regulation (eqns 8 and 18) relative to the life history at population dynamic equilibrium, instead of defining them relative to a hypothetical never-experienced-maximum as in traditional density-regulated models (eqn 16).

Taken together these findings define a new ecological paradigm. A case where the world is green because the densities of populations are naturally selected by the density-frequency-dependent resource bias from intraspecific interactive competition, instead of being determined by famine from intense competition for depleted resources, as proposed by Malthus (1798) and developed in density-regulated models (Verhulst 1838; Pearl and Reed 1920; Lotka 1925). While some individuals win and others loose in interactive competition, the frequency of competition at evolutionary equilibrium is selected to a level where all individuals end up with sufficient resources for the same optimal rates of reproduction and survival. For species that are selected at an evolutionary steady state with an exponentially increasing body mass (Witting 1997, 2020), the frequency of competition is somewhat higher (eqn 27) generating an intra-specific reproductive rate that increases in approximate proportion with body mass, as observed in many species (e.g., Peters 1983; Reiss 1989; Kingsolver and Pfennig 2004).

\subsection{Predicting animal abundance}

Where traditional density regulation struggles to explain the abundance of animal populations (May 2020), we may use population dynamic feedback selection to predict changes $\left(\partial \ln n^{*} / \partial \ln x\right)$ in the equilibrium abundance $\left(n^{*}\right)$ as a function of evolutionary changes in other traits $(x)$.

For this we may focus on the evolutionarily determined population dynamic equilibria. These are competitive interaction fixpoints

$$
\begin{aligned}
\iota^{* *} & =1 / \psi \\
\iota^{* s} & =(4 d-1) /(2 d-1) \psi
\end{aligned}
$$

that predict the log-level of interactive competition $\left(\iota^{* *}\right.$ or $\iota^{* s}$ ) for a body mass in evolutionary equilibrium $(* *)$ or steady state $(* s)$, with $d$ being the dominant spatial dimensionality of the competitive foraging ecology, and $\psi$ the intra-specific gradient in resource access per unit interference across the body mass variation in the population (details by Witting 1997, 2017a,b). For species with similar modes of selection and competition we expect an invariant gradient and thus also an invariant level of intra-specific competition.

The interference of eqn 27 is determined by a feedback selection that adjusts the underlying ecological factors that mechanistically generate the interactive competition in the population. This generation of interference is rather complex depending not only on population density, but also on foraging speed and homerange size, with individuals competing mainly in the areas where home ranges are overlapping. It is this interactive foraging in the spatial ecology of overlapping home ranges that generates the net energy that is selected into body mass, with the joint selection equilibrium for the foraging process and body mass predicting the evolution of body mass allometries (Witting 1995, 2017a).

Apart from physiological traits like metabolism and life periods, the predicted allometries include ecological traits like home range and abundance, with the body mass $(w)$ allometry for abundance being $n^{*} \propto w^{\hat{n}}$ with a theoretically predicted exponent

$$
\hat{n}=(1-2 d) / 2 d
$$

that depends on the dominant number of spatial dimensions $(d \in\{1,2,3\})$ in the foraging ecology.

The inter-specific body mass invariance that relates to the invariance of eqn 27 is $n^{*} w^{-\hat{n}}$ from $n^{*} \propto w^{\hat{n}}$, 
with $\iota^{* *} \propto \ln n^{*}-\hat{n} \ln w$. But this relation relates only to cases with an inter-specific body mass invariant resource bias gradient $(\psi)$. More generally we may, dependent upon the scale of observation, expect an interspecific resource partitioning by interactive competition, where larger species have access to more resources than smaller species. Assuming that the individuals of a species compete less per encounter when resources are abundant, this implies a body mass dependence $\ln \psi \propto \hat{\psi} \ln w$ with an exponent $(\hat{\psi})$ that decline from zero to some lower negative value with an increase from zero in the level of inter-specific resource partitioning. The predicted change in abundance with body mass is thus

$$
\frac{\partial \ln n^{*}}{\partial \ln w}=\hat{n}-\hat{\psi}
$$

As each bird species has its own probability that an individual is detected by an observer, the point-counts of the BBS are unsuited for a generation of comparable density estimates across species. We may instead refer to Nee et al. (1991) that used the unusually good population size estimates of British and Swedish birds to examine the relationships between body mass and abundance. At the scale of all species-where we can expect a $\hat{\psi}$ exponent of zero owing to the general lack of competition between waterfowl, shorebirds, raptors, and passerines - Nee et al. (1991) estimated a partial $\partial \ln n^{*} / \partial \ln w$ relation of -0.75 among British birds, and -0.77 among Swedish, as predicted by eqns 28 and 29 given a predominantly two-dimensional distribution of territories. At smaller scales there was a significant positive relation between abundance and body mass in agreement with a within tripe partitioning of resources from inter-specific competition. Nee et al. (1991) did not quantify these relations but for, e.g., an approximate proportional distribution of resources with a $\hat{\psi}$ exponent around -1 we predict a body mass response around $\partial \ln n^{*} / \partial \ln w=0.25$.

Another interesting prediction reflects the relationship between abundance and ecological variation in mortality. Traditional non-selection based limitation (Sinclair 1989) predicts a straightforward decline in abundance with increased mortality. Population dynamic feedback selection, however, buffers this response by a selection where net energy is reallocated from body mass (or competitive quality more generally) into enhanced reproduction until the level of interference at the competitive interaction fixpoint is re-established. This argues for an invariance between ecological mortality and abundance, but we expect also an allometric effect where a selected decline in body mass with increased mortality generates an increase in abundance.
It is widely documented that the body mass of species tends to decline with increased mortality (e.g., Reznick et al. 1996; Haugen and Vøllestad 2001; Sinclair et al. 2002; Coltman et al. 2003; Carlson et al. 2007; Herczeg et al. 2009; Rossetto et al. 2012), and an increase in abundance with increased mortality is also documented in birds and mammals (Witting 2021a,d).

Another intriguing relation relates to the differences in population densities between birds and mammals. Even though the average mammal is about four times larger than the average bird, the population densities of mammals are about twenty times higher than the densities of birds. This difference is similar in magnitude to a natural selection predicted difference, should birds have predominantly body masses in evolutionary equilibrium and mammals predominantly body masses at evolutionary steady state with selection for an exponential increase in net energy and mass (Witting 2021b).

\subsection{Life history evolution}

The proposed union of life history selection and population dynamics reflects the interdependence of the two. The feedback selection for the competitive quality of body mass, group size, and sexual reproduction depends on population dynamic growth, and this paper shows that the population dynamics around the evolutionary equilibrium is driven predominantly by the selection regulation of population dynamic feedback selection.

On the larger evolutionary scale from self-replicating molecules to multicellular animals, it has been shown that the evolutionary unfolding of population dynamic feedback selection (from population dynamic growth and the selection of ability to monopolise resources in interactive competition) predicts the natural selection of metabolism, mass, and life history allometries from virus, over prokaryotes, and larger unicells to multicellular animals with sexual reproduction (Witting 2017a,b).

It is, however, only in multicellular animals that we predict a fully developed feedback selection (Witting 2017b). It is only here that we expect a balancing selection regulation with growth rate deceleration and increased competitive quality when the abundance is above the equilibrium, and growth rate acceleration and decreased competitive quality below the equilibrium.

Vira and prokaryotes are predicted to evolve without the decelerating selection from a biased resources access by interactive competition, leaving these taxa with stable selection for accelerating growth (as illustrated, e.g., with the evolution of faster-spreading Covid-19 
variants; Kupferschmidt 2021). Larger unicells are predicted to have some resource bias from interactive competition, yet the feedback selection should be incompletely developed and - at least in most casesexpected to be unable to decelerate population dynamic growth.

\section{Supplementary Information}

Not available in this pre-print, but the population models are available at https://mrLife.org.

si1: BBS trajectory and distribution plots;

si2: BBS population trajectories;

si3: List of BBS populations;

si4: Plots of AIC-selected population models.

\section{Acknowledgements}

I thank all that have collected and published the population data I used.

\section{Appendix}

\section{A Dynamic behaviour}

The population dynamic behaviour of the discrete selection-regulated equations with non-overlapping generations (eqns 7 and 8) was described by Witting (1997, 2000b). This model has damped population cycles when $\gamma_{\iota}<\gamma$, neutrally stable cycles when $\gamma_{\iota}=\gamma$, and repelling cycles when $\gamma_{\iota}>\gamma$. The population period of the stable cycles increases from four to an infinite number of generations as the $\gamma_{\iota}=\gamma$ parameters decline from two to zero. For a given $\gamma$ the period increases with a decline in $\gamma_{\iota}$, i.e., with an increasingly damped cycle. When, for a stable cycle, $\gamma_{\iota}=\gamma$ increases from two to four, there is an extra period in the amplitude of the population period, with the latter declining monotonically to two generations; with the dynamics becoming chaotic when $\gamma_{\iota}=\gamma$ increases beyond four.

The age-structured model with overlapping generations behave in a similar way, but the dynamics depend also on the age of reproductive maturity $\left(a_{m}\right)$ and the reproductive period $\left[t_{r}=1 /(1-p)\right]$. The age-structured model converges on the discrete model as $a_{m} \rightarrow 1$, $t_{r} \rightarrow 1$, and $p \rightarrow 0$. The period $(T)$ of the stable population cycle remains a declining function of $\gamma$ (Fig. 7b), with the slope/exponent $(\beta)$ of the $\ln T \propto \beta \ln \gamma$ relation being -0.5 (estimated by linear regression). The cyclic dynamics become more and more stable with a decline in $\gamma_{\iota}$, but the damping is also dependent on $a_{m}$ and $t_{r}$. The stable cycle, e.g., has a $\gamma_{\iota} / \gamma$ ratio that increases beyond unity as $a_{m}$ and $t_{r}$ increase above unity (Fig. $7 \mathrm{a}$ and $\mathrm{c}$ ). For any given combination of $a_{m}$ and $t_{r}$, the stable cycle has a $\gamma_{\iota} / \gamma$ ratio that is almost constant (Fig. 7a).

For a given $\gamma$, the period of the stable population cycle increases almost linearly with an increase in $a_{m}$ and $t_{r}$ (Fig. 7d), with the period dependence on $\gamma$ being somewhat elevated relative to the discrete model where $a_{m}=t_{r}=1$ (Fig. 7b). Hence, for populations where $\gamma$ is independent of $a_{m}$ and $t_{r}$, we can expect an approximate linear relation between the population period $T$ and life history periods like $a_{m}$ and $t_{r}$. This implies a population cycle allometry, where $T$ is expected to scales with the $1 / 4$ and $1 / 6$ power of body mass across species with intra-specific competition in two and three spatial dimensions (Witting 1995, 2017).

When only one parameter is altered at the time, the period is almost invariant of $\gamma$ (Fig. 7f). This reflects that the decline in period with an increase in $\gamma$ for dynamics with a given damping ratio, is counterbalanced by the increase in period that is caused by the increased stability of the cycle, as the $\gamma_{\iota} / \gamma$ ratio - that defines the damping ratio-declines with the increase in $\gamma$. For single parameter perturbations, the damping ratio is usually most strongly dependent on $\gamma$ and $\gamma_{\iota}$, showing only a small increase with $t_{r}$ and a small decline with an increase in $a_{m}$ (Fig. 7e).

\section{B Ecological structure}

The different dynamics and key parameter estimates are listed in Table 4 for six ecotypes of North American birds, with the geographical distributions of key parameters shown in Fig. 8.

Given the many types of dynamics (two hyperexponential versions, four damping ratio categories, and three equilibrium conditions) key parameters give a restricted description of the overall dynamics. The average growth rate, e.g., might be zero when a population is increasing and declining through stable cycles.

Keeping these limitations in mind, the split between populations with an average positive or negative realised growth rate is almost even across all 335 accepted population dynamic models. The median for the average realised growth rate is $0.0018(95 \%$ :-0.069-0.09) 

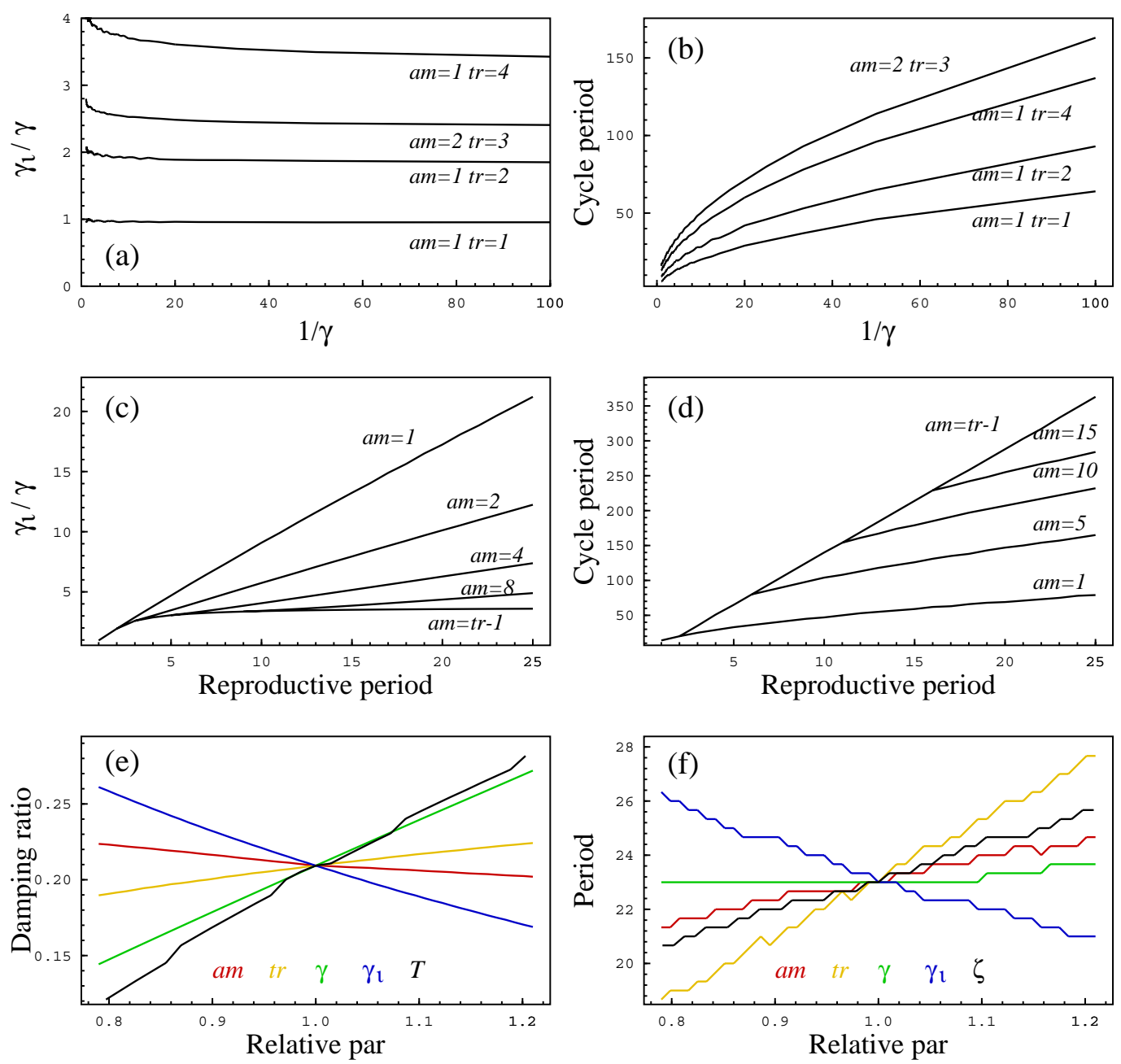

Figure 7: Dynamic behaviour. Plot a to d: The $\gamma_{\iota} / \gamma$-ratio, and period (in years), of a stable population cycle $(\zeta=0)$ as a function of $1 / \gamma$ (plot $\mathbf{a}$ and $\mathbf{b}$ ) and the reproductive period (plot $\mathbf{c}$ and $\mathbf{d}$ for $\gamma=0.2$ ), for different combinations of $t m$ and $t r$. Plot e and f: The damping ratio $(\zeta)$ and population period $(T)$ as a function of the parameters $x \in\left\{a m, t r, \gamma, \gamma_{\iota}, \zeta, T\right\}$, relative $(x / \hat{x})$ to the parameter point estimates $\hat{x} \in\left\{a m=1, \operatorname{tr}=2.8, \gamma=0.51, \gamma_{\iota}=0.76, \zeta=0.21, T=23\right\}$ of a mallard (Anas platyrhynchos) population. The dependence on $T$ in plot $\mathbf{e}$, and on $\zeta$ in plot $\mathbf{f}$, is given by their responses to changes in $\gamma_{\iota}$.

with 176 populations having a positive average growth rate, and 159 having a negative. Despite of the even margin, there are predominantly more populations with a positive average growth rate than negative across the North American continent, except for a small central area on the east coast (Fig. 8, top row). There is an equally even split between populations with increasing (99) or declining (89) equilibrium densities. The northern and some coastal areas in the east and west have more populations with declining than increasing equilibria, although the majority of North America have more populations with increasing equilibria.

Among the populations with selection-dynamics, the strength of selection regulation $\left(\gamma_{\iota}\right)$ is stronger than density regulation $(\gamma)$, with $\gamma_{\iota} / \gamma$-ratios of 1.5 (95\%:0.15-30,000), and 158 populations having $\gamma_{\iota} / \gamma$ ratios above unity, and 90 populations ratios below. This bias is apparent throughout the continent, where selection regulation is stronger than density regulation in most populations throughout, except for the west coast - and single areas in the north and east - where density regulation is stronger than selection regulation in most species.

The realisation of selection into an acceleration, or deceleration, of the growth rate depends on relative abundance $\left(n / n^{*}\right)$. With the median of the average 
selection response $[\dot{r}=-0.00099(95 \%:-0.042-0.047)]$ being around zero, the average population abundance is close to equilibrium. The split is almost even, with 142 populations being on average below the equilibrium with accelerating growth, and 172 being on average above with decelerating growth. Population growth is predominantly decelerating across the continent, except on the east and west coast and in the north where it is predominantly accelerating in some areas. The accumulated regulation over the survey period produced stronger selection regulation than density regulation in the majority of populations in all areas.

This overall pattern reflects a variety of underlying patterns across the ecotypes of North American birds.

\section{Waterfowl (Ardeidae, Ciconiidae, Phoeni-} copteridae, Threskiornithidae, Gruidae, Anatidae, Aramidae, Rallidae, Jacanidae): Waterfowl with accepted models (23 populations) have a positive median average growth rate $[r=0.02$ (95\%:-0.073$0.48)$ ], reflecting an average increase in 14 populations, and an average decline in 9. Part of the increase is caused by a larger (0.60) than average (0.40) fraction of populations with an increasing equilibrium, and a much smaller (0.13) than average (0.36) fraction with a declining equilibrium. As shown in the second row of Fig. 8, more than half of the waterfowl populations have positive growth and increasing equilibria throughout the continent, except for the west coast and a few areas in the east where negative average growth is dominant.

Among the ecotypes examined, waterfowl have a close to average selection regulation with a relative strength of $\gamma_{\iota} / \gamma=1.4$ (95\%:0.26-10,000). This reflects a selection regulation that is stronger than density regulation in 9 populations, while the opposite is the case in 6 populations. Populations with stronger regulation by selection than density dominate the whole continent, except that density regulation dominates in the few areas in the north and on the west coast where the equilibrium abundance is predominantly declining.

The selection regulation in waterfowl produced an average growth rate deceleration of -0.0071 (95\%:-0.036-0.036), based on 14 populations that were on average above the equilibrium with decelerating growth, and 7 populations with accelerating growth below the equilibrium. The widespread deceleration of growth in waterbirds is, among others, estimated by a much larger (0.26) than average (0.15) fraction of decelerating hyper-exponential models. Deceleration dominates all areas, apart from the few northern and west coast areas where $n^{*}$ is predominantly declining and density regulation is stronger than selection regulation. The same pattern is apparent for the accumulated regulation over the survey period where selection dominates density in most populations in most areas.

\section{Shorebirds (Haematopodidae, Recurvirostridae, Charadriidae, Scolopacidae, Laridae): Shore-} birds with accepted models (12 populations) have the strongest negative growth of all ecotypes, with an average growth rate estimate of -0.014 (95\%:-0.56-0.2), reflecting a decline on average in 7 populations, and an increase in 5. Part of the decline is caused by a larger (0.71) than average (0.36) fraction of populations with a declining equilibrium, and a smaller (0.14) than average $(0.40)$ fraction with an increasing equilibrium. More shorebirds have declining than increasing equilibria across the continent (apart from a single area in northwest), and negative growth is dominant in the western and eastern areas, with positive growth dominating the central east and scattered small areas in the north (Fig. 8, third row).

The relative strength of selection regulation in shorebirds is about similar with the average across all species. This reflects a selection regulation that is stronger than density regulation in 4 populations, while the opposite is the case in 3 populations. Selection regulation dominates density regulation in the western areas, while density regulation is stronger than selection regulation in the east.

Selection regulation in shorebirds produced the strongest deceleration of growth across all ecotypes. The estimated $\dot{r}=-0.015$ (95\%:-0.45-0.085) reflects and 8 populations with decelerating growth on average, and 4 with accelerating growth. It is only in the southwest that most shorebirds were on average below the equilibrium with accelerating growth, while the continent is dominated by decelerating growth in shorebirds that were on average above the equilibrium.

With a $\Delta \tilde{r}_{s / r}$ estimates of 0.9 (95\%:0.29-1), regulation in shorebirds is caused almost entirely by selection. This is also apparent in the geographical distribution, where accumulated selection regulation outweighs density regulation in most populations in all areas, except from a single small area in south-east.

Raptors (Cathartidae, Pandionidae, Accipitridae, Falconidae): Raptors with accepted models (14 populations) have the strongest positive growth of the ecotypes. The average per-generation growth rate was estimated to 0.042 (95\%:-0.038-0.38), with 12 populations having positive growth on average, while growth was negative in 2. This reflects among others a larger 


\begin{tabular}{l|cccccccc} 
& BBS & WAT & SHO & RAP & INS & SEE & GRO & RES \\
\hline$n$ & 462 & 31 & 21 & 16 & 110 & 57 & 62 & 165 \\
$n_{m}$ & 335 & 23 & 12 & 14 & 86 & 40 & 48 & 112 \\
\hline$e$ & 0.04 & 0.04 & 0 & 0.21 & 0 & 0 & 0.06 & 0.05 \\
$h_{\dot{r} \uparrow}$ & 0.05 & 0 & 0 & 0.21 & 0.01 & 0.05 & 0.04 & 0.07 \\
$h_{\dot{r} \downarrow}$ & 0.15 & 0.26 & 0.42 & 0.21 & 0.16 & 0.12 & 0.06 & 0.12 \\
$d$ & 0.02 & 0.04 & 0 & 0 & 0 & 0.07 & 0.04 & 0.02 \\
$s$ & 0.74 & 0.65 & 0.58 & 0.36 & 0.83 & 0.75 & 0.79 & 0.73 \\
\hline$\gamma_{\iota} / \gamma$ & 1.5 & 1.4 & 1.3 & 1.8 & 1.7 & 1.3 & 1.1 & 1.3 \\
$\dot{r}$ & -.099 & -.71 & -1.5 & 1.8 & $5.7 e-5$ & -.19 & -.11 & -.034 \\
$\Delta \tilde{r}_{s / r}$ & .75 & .77 & .9 & 1 & .72 & .74 & .75 & .74 \\
$r$ & .18 & 2 & -1.4 & 4.2 & .75 & -.67 & -.88 & .1 \\
\hline$\zeta_{s}$ & 0.04 & 0.07 & 0 & 0 & 0.04 & 0.03 & 0 & 0.05 \\
$\zeta_{m}$ & 0.38 & 0.47 & 0.57 & 0.40 & 0.32 & 0.33 & 0.47 & 0.38 \\
$\zeta_{w}$ & 0.30 & 0.20 & 0.14 & 0.60 & 0.31 & 0.37 & 0.21 & 0.33 \\
$\zeta_{n}$ & 0.28 & 0.27 & 0.29 & 0 & 0.32 & 0.27 & 0.32 & 0.24 \\
\hline$n^{*} \rightarrow$ & 0.24 & 0.27 & 0.14 & 0 & 0.25 & 0.17 & 0.32 & 0.24 \\
$n^{*} \uparrow$ & 0.40 & 0.60 & 0.14 & 0.80 & 0.46 & 0.47 & 0.29 & 0.33 \\
$n^{*} \downarrow$ & 0.36 & 0.13 & 0.71 & 0.20 & 0.28 & 0.37 & 0.39 & 0.43 \\
\hline & & & & & & & &
\end{tabular}

Table 4: Model details Key parameters and model categories for all species in the Breeding Bird surveys (BBS), and for waterfowl (Wat), shorebirds (Sho), raptors (Rap), tree living insect-eaters (Ins), seed-eaters (See), ground living passerines (Gro), and species not included in the six ecotypes (Res). $n$ is the total number of populations with index trajectories, $n_{m}$ the number with accepted models, with model fractions for exponential growth $(e)$, hyper-exponentially accelerating $\left(h_{\dot{r} \uparrow}\right)$, hyperexponentially deceleration $\left(h_{\dot{r} \downarrow}\right)$, density-regulated $(d)$, selection-regulated $(s)$, with fractions of the latter for strongly $\left(\zeta_{s}\right)$, medium $\left(\zeta_{m}\right)$, weak $\left(\zeta_{w}\right)$, and negatively $\left(\zeta_{n}\right)$ damped dynamics, as well as populations with stable $\left(n^{*} \rightarrow\right)$, increasing $\left(n^{*} \uparrow\right)$, or declining $\left(n^{*} \downarrow\right)$ equilibria. Listed is also the distribution median for the strength of selection regulation over density regulation $\left(\gamma_{\iota} / \gamma\right)$, growth rate acceleration $(\dot{r})$, accumulated selection regulation relative to accumulated total regulation $\left(\Delta \tilde{r}_{s / r}\right)$, and the per-generation growth rate $(r)$.

(0.80) than average $(0.40)$ fraction of populations with increasing equilibria, and a smaller (0.20) than average fraction (0.36) with declining equilibria. Positive growth and increasing equilibria dominate the whole continent (Fig. 8, fourth row).

The strength of selection regulation was stronger than density regulation in 5 populations, while the opposite was the case in 0 , with $\gamma_{\iota} / \gamma=1.8$ (95\%:1.1-2.4). Selection regulation is stronger than density regulation in most populations in all areas.

Among the ecotypes examined, raptors were estimated to have the strongest growth rate acceleration on average, with an estimate of $\dot{r}=0.018$ (95\%:-0.0093-
0.058), with 8 populations being on average below their equilibria with accelerating growth, and 3 having decelerating growth above their equilibria. This acceleration is estimated in part by a much larger (0.21) than average (0.05) fraction of accelerating hyper-exponential models. Accelerating growth rates dominate all areas, apart from a few small areas in the south-west and north-east.

With a $\Delta \tilde{r}_{s / r}$ estimates of 1 (95\%:0.54-1), regulation in raptors is driven almost entirely by selection. This is also apparent in the geographical distribution, where accumulated selection regulation outweighs density regulation in all areas. 
bioRxiv preprint doi: https://doi.org/10.1101/2021.11.27.470201; this version posted November 27, 2021. The copyright holder for this

preprint (which was not certified by peer review) is the author/funder, who has granted bioRxiv a license to display the preprint in perpetuity. It is made available under aCC-BY-NC-ND 4.0 International license.
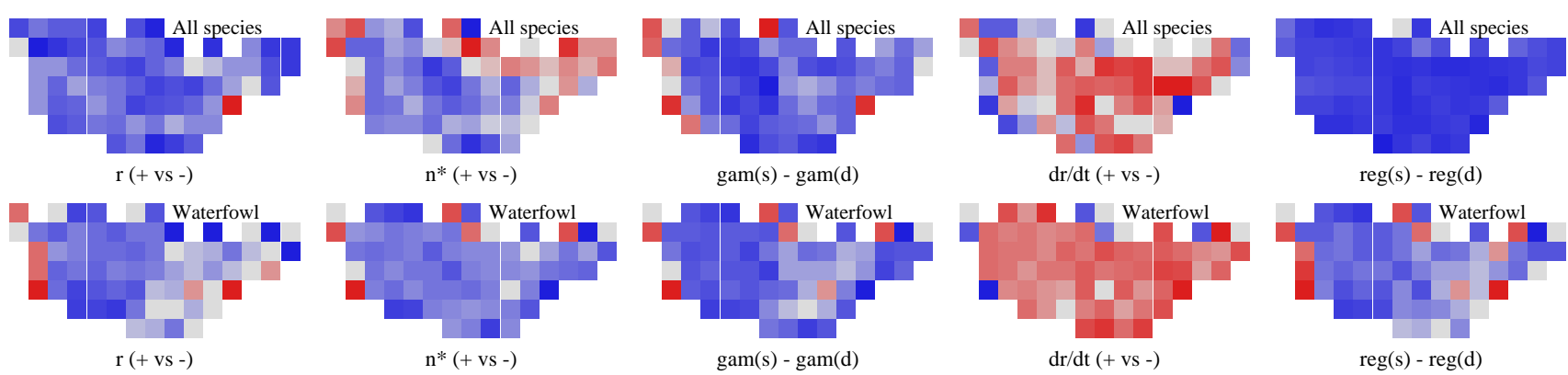

$\operatorname{reg}(\mathrm{s})-\operatorname{reg}(\mathrm{d})$
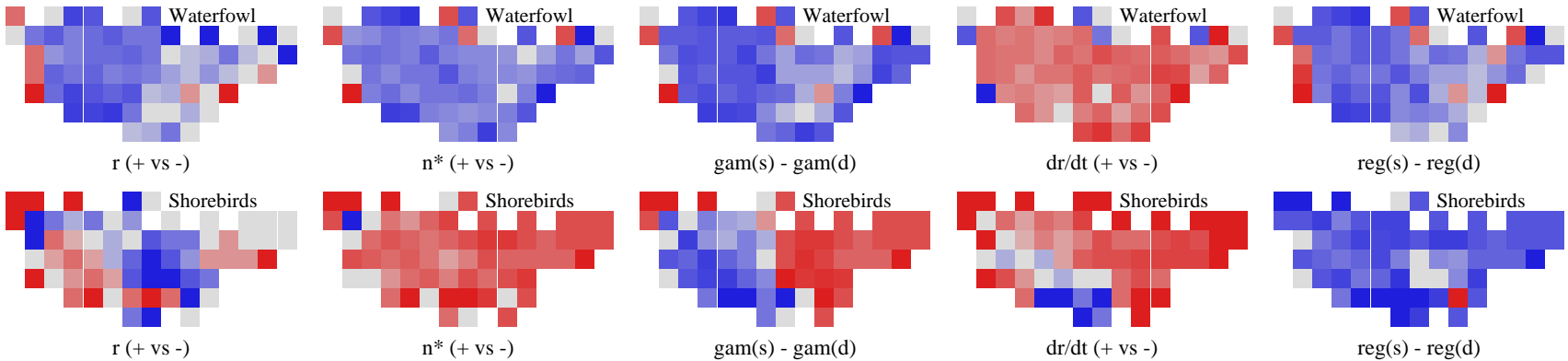

$\operatorname{reg}(\mathrm{s})-\operatorname{reg}(\mathrm{d})$
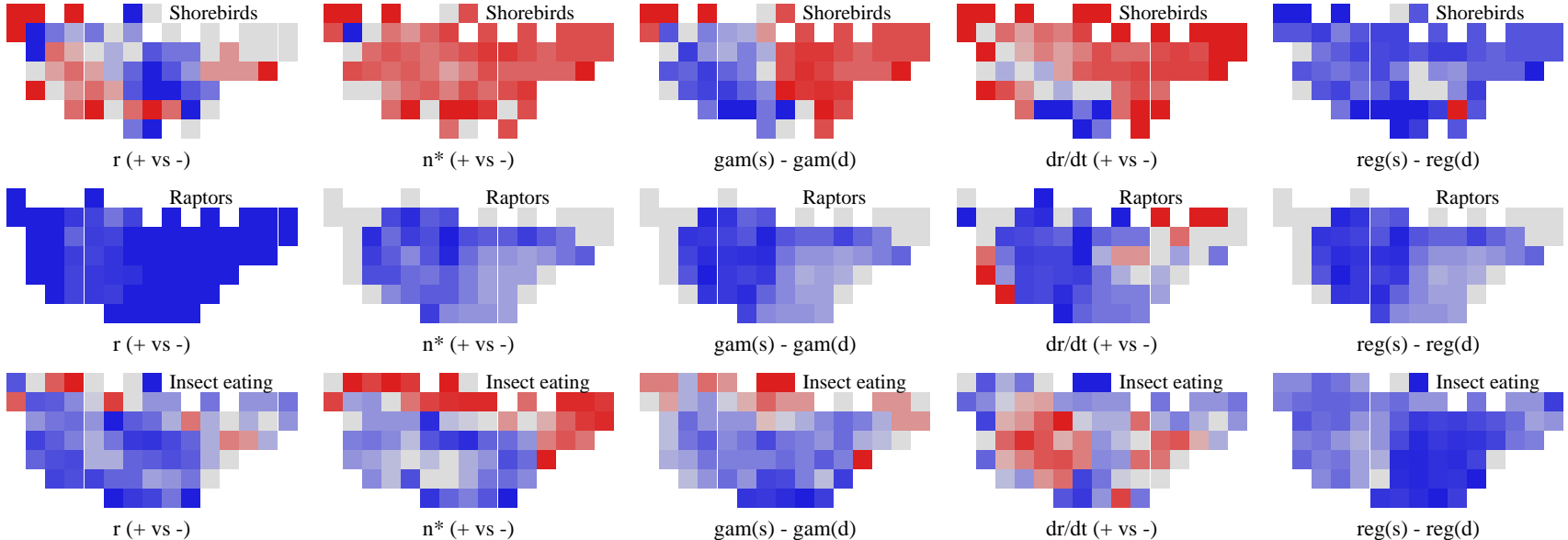

$\operatorname{reg}(\mathrm{s})-\operatorname{reg}(\mathrm{d})$
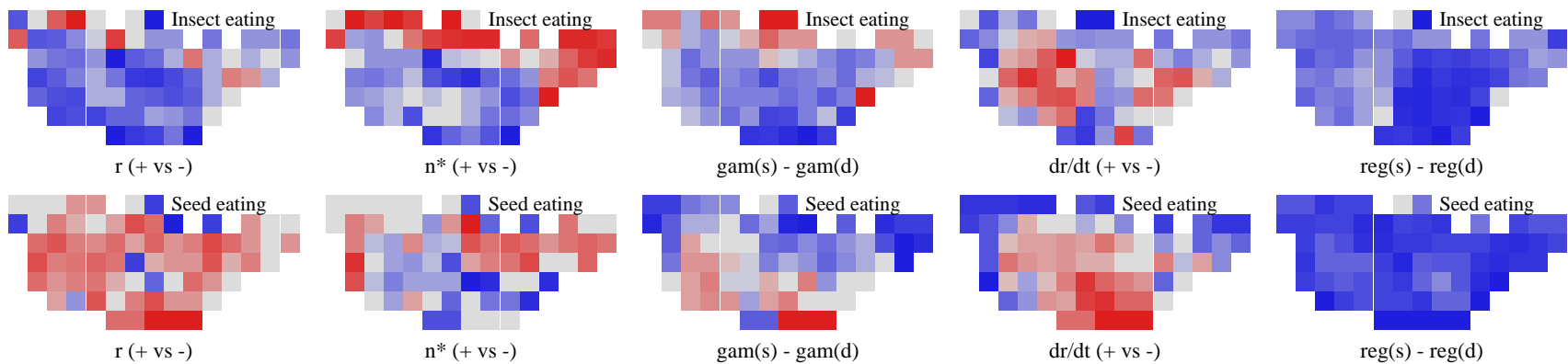

$\operatorname{reg}(\mathrm{s})-\operatorname{reg}(\mathrm{d})$

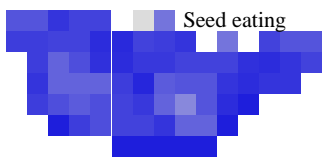

$\operatorname{reg}(s)-\operatorname{reg}(d)$
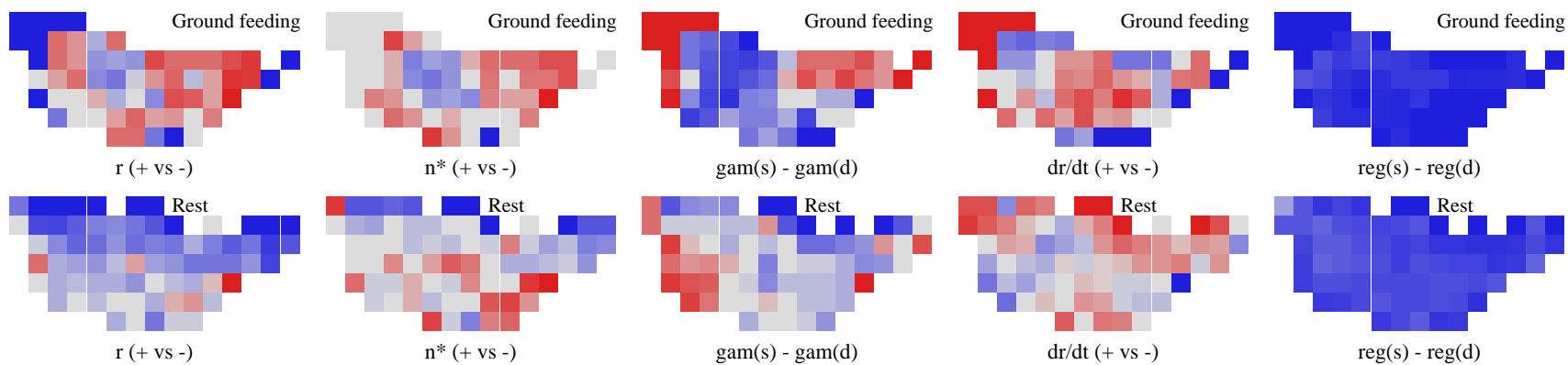

Figure 8: Selection maps. The geographical distributions for the proportions of populations with a positive (blue) or negative (red) average growth rate ( $r$, left); an increasing (blue) or declining (red) equilibrium $\left(n^{*}\right)$ (second left); a positive or negative difference $\left(\gamma_{\iota}-\gamma\right)$ between the strengths of selection regulation $\left(\gamma_{\iota}\right)$ and density regulation $(\gamma$, middle); an accelerating (blue) or decelerating (red) growth rate (dt/dt, second right); and a positive or negative difference $\left(\Delta r_{s}-\Delta r_{d}\right)$ between the realised selection regulation $\left(\Delta r_{s}\right)$ and density regulation $\left(\Delta r_{d}\right)$ for accepted models across all species and seven ecotypes. The intensities of red and blue increase with larger absolute values. 
Tree living insect eating passerines (flycatchers, vireos, warblers, kinglets): Insect eating passerines with accepted models (86 populations) are somewhat dominated by positive growth, with average growth rates of 0.0075 (95\%:-0.047-0.056), and 54 populations having positive growth on average, and 32 populations negative. The fraction (0.46) of populations with increasing equilibria is slightly above average $(0.40)$, and slightly fewer (0.28) than average (0.36) had declining equilibria. More populations with positive than negative growth is the norm over the whole continent, apart from few scattered small areas with predominantly negative growth in the north. The population equilibria were predominantly increasing, apart from northern areas (especially in the east) where they were predominantly declining.

Tree living insect eaters were found to have the second strongest selection regulation, with a relative strength of $\gamma_{\iota} / \gamma=1.7$ (95\%:0.037-7,700). Selection regulation is stronger than density regulation in 49 populations, while density regulation is strongest in 22 populations. The bias towards selection regulation is apparent in all areas, except that density regulation dominates selection regulation in some of the northern and eastern areas with predominantly declining equilibria.

The average growth rate accelerations in insect eaters were about zero with estimates of $5.7 e-7$ (95\%:-0.02$0.013)$, reflecting 44 populations with an accelerating growth rate on average, and 42 with a decelerating growth rate. The even split is reflected in a geographical pattern where deceleration in populations above the equilibrium is dominating central eastern and western areas, while acceleration below the equilibrium dominates the coastal areas, north and south, and a central area running from north to south. The accumulated selection regulation is close to the BBS average, with $\Delta \tilde{r}_{s / r}$ estimates of 0.72 (95\%:0.37-1). Accumulated selection regulation dominates density regulation in most populations in all areas.

Seed eating passerines (finches, sparrows, larks, grossbeaks, longspurs): Seed eating passerines with accepted models (40 populations) have negative growth on average, with an estimate of -0.0067 (95\%:-0.0570.057 ), based on 24 populations with negative growth, and 16 with positive. The negative growth is not driven by declining equilibria, as a larger $(0.47)$ than average (0.40) fraction have increasing equilibria, while the fraction with declining equilibria $(0.37)$ is about average (0.36). Equilibria are predominantly increasing in the south and central west, while they are predominantly declining in the north-east and west. The strength of selection regulation is stronger than density regulation in $60 \%$ of the populations, and in most populations in most areas, except from areas in the south. There is an average deceleration of growth $[\dot{r}=-0.0019$ (95\%:-0.032-0.025)], with $65 \%$ of the populations being on average above their equilibria with decelerating growth. Growth rate deceleration dominates the central and southern part of the continent, with growth rate acceleration occurring in the north and along the coasts. The accumulated selection regulation is close to the BBS average, with accumulated selection regulation dominating density regulation in most populations in all areas.

Ground living passerines (thrushes, blackbirds, starlings, thrashers, accentors, pipits): Ground living passerines with accepted models (48 populations) have the strongest negative growth of all ecotypes, with an average estimate of -0.0088 (95\%:-0.13-0.046), based on 30 populations with negative growth, and 18 populations with positive. They have a slightly larger $(0.39)$ than average (0.36) fraction with declining equilibria, and a slightly smaller (0.29) than average (0.40) fraction with increasing equilibria. Negative growth and declining equilibria dominate in the east and in a central south to north-west band, while the central west have predominantly increasing populations and equilibria, with the west and north-west having increasing populations as well.

The strength of selection regulation is close to the BBS average, with selection regulation being stronger than density regulation in $61 \%$ of the populations, and in most populations in the south and central west, while density regulation in dominant in most populations in the north-east and north-west.

The average growth rates are decelerating at estimated rates of -0.0011 (95\%:-0.017-0.014) with $63 \%$ of the populations being on average above the equilibrium with decelerating growth. This growth deceleration is dominant in the central parts and along the west coast, with acceleration in populations below their equilibria dominating the south and in some areas in the north and along the east coast. The accumulated selection regulation is again dominating density regulation in most populations in all areas.

Remaining species that are not included in the defined ecotypes have accepted models for 112 populations. The estimated average growth is small 0.001 (95\%:-0.099-0.085), with 57 populations having positive growth, and 55 populations negative. They have about average fractions of populations with declining, 
increasing, and stable equilibria. Positive growth dominates most areas, with equilibrium densities tending to increase in the northern areas and decline in the southern areas.

The strength of selection regulation relative to density regulation is about average, with selection regulation being stronger than density regulation in $61 \%$ of the populations, and in most populations in most areas, except for the west and in few scattered areas. The average growth rates are about stable with an estimated deceleration of -0.00034 (95\%:-0.041-0.067) with $52 \%$ of the populations being on average above equilibrium with decelerating growth. The even split is represented by a general growth rate deceleration towards the east and north-west, and acceleration towards the west. The accumulated selection regulation is again dominating density regulation in most populations in all areas.

\section{References}

Agashe D. (2009). The stabilizing effect of intraspecific genetic variation on population dynamics in novel and ancestral habitats. Am. Nat. 174:255-267.

Akaike H. (1973). Information theory as an extension of the maximum likelihood principle. In: Petrov B. N. Csaki F. (eds). Second International Symposium on Information Theory: Akademiai Kiado, pp 267-281.

Beckerman A., Benton T. G., Ranta E., Kaitala V., Lundberg P. (2002). Population dynamic consequences of delayed life-history effects. Trends Ecol. Evol. 17:263269.

Bell G. (2017). Evolutionary rescue. Ann. Rev. Ecol. Evol. Syst. 48:605-627.

Bell G. Gonzalez A. (2009). Evolutionary rescue can prevent extinction following enviromental change. Ecol. Lett. 12:942-948.

Berryman A. A. (1996). What causes population cycles of forest lepidoptera? Trends Ecol. Evol. 11:28-32.

Boonstra R. Krebs C. J. (1979). Viability of large- and small-sized adults in fluctuating vole populations. Ecology 60:567-573.

Brunner F. S., Deere J. A., Egas M., Eizaguirre C., Raeymaekers J. A. M. (2019). The diversity of ecoevolutionary dynamics: Comparing the feedbacks between ecology and evolution across scales. Funct. Ecol. $33: 7-12$.

BTO (2020). Population trend graphs. British Trust for Ornithology, https://www.bto.org.

Carlson S. M., Edeline E., Vollestad A. L., Haugen T. O., Winfield I. J., Fletcher J. M., Ben James J., Stenseth N. C. (2007). Four decades of opposing natural and human-induced artificial selection acting on Windermere pike (Esox lucius). Ecol. Lett. 10:512-521.
Chitty D. (1952). Mortality among voles (Microtus agrestis) at Lake Vyrnwy, Montgomeryshire in 1936-9. Phil. Trans. R. Soc. Lond. 236:505-552.

Chitty D. (1960). Population processes in the voles and their relevance to general theory. Can. J. Zool. 38:99-113.

Coltman D. W., O'donoghue P., Jorgenson J. T., Hogg J. T., Strobeck C., Festa-Bianchet M. (2003). Undesirable evolutionary consequences of trophy hunting. Nature 426:655-658.

Coulson T., Macnulty D. R., Stahler D. R., Vonholdt B., Wayne R. K., Smith D. W. (2011). Modeling Effects of Environmental Change on Wolf Population Dynamics, Trait Evolution, and Life History. Science 334:12751278.

DOF (2020). Punkttællinger. Dansk Ornitologisk Forening, https://www.dof.dk.

Ergon T., Lambin X., Stenseth N. C. (2001). Life-history traits of voles in a fluctuating population respond to the immediate environment. Nature 411:1043-1045.

Ginzburg L. R. (1972). The analogies of the "free motion" and "force" concept in population theory (in Russian). In: Ratnar V. A. (ed). Studies on theoretical genetics: Academy of Sciences of the USSR, Novosibirsk, pp 6585.

Ginzburg L. R. (1998). Inertial growth. Population dynamics based on maternal effects. In: Mousseau T. A. Fox C. W. (eds). Maternal effects as adaptations: Oxford University Press, New York, pp 42-53.

Ginzburg L. R. Taneyhill D. E. (1994). Population cycles of forest lepidoptera: a maternal effect hypothesis. J. Anim. Ecol. 63:79-92.

Gomulkiewicz R. Holt R. D. (1995). When does evolution by natural selection prevent extinction? Evolution 49:201-207.

GPDD (2010). The Global Population Dynamics Database v2.0. NERC Centre for Population Biology, Imperial College, http://www.sw.ic.ac.uk/cpb/cpb/gpdd.html.

Graham I. M. Lambin X. (2002). The impact of weasel predation on cyclic field-vole survival: the specialist predator hypothesis contradicted. J. Anim. Ecol. 71:946956.

Hairston N. G. J., Ellner S. P., Geber M. A., Yoshida T., Fox J. A. (2005). Rapid evolution and the convergence of ecological and evolutionary time. Ecol. Lett. 8:11141127.

Hairston S. N. G., Smith F. E., Slobodkin L. B. (1960). Community structure, population control, and competition. Am. Nat. 94:421-425.

Hansen T. F., Stenseth N. C., , Henttonen H. (1999a). Multiannual vole cycles and population regulation during long winters: an analysis of seasonal density fependence. Am. Nat. 154:129-139.

Hansen T. F., Stenseth N. C., Henttonen H., Tast J. (1999b). Interspecific and intraspecific competition as causes of direct and delayed density dependence in a 
fluctuating vole population. Proc. Nat. Acad. Sci. USA 96:986-991.

Hansson L. (1969). Spring populations of small mammals in central Swedish Lapland in 1964-1968. Oikos 20:431450.

Haugen T. O. Vøllestad L. A. (2001). A century of lifehistory evolution in grayling. Genetica 112:475-491.

Hendry A. P. (2017). Eco-evolutionary dynamics. Princeton University Press, Princeton.

Herczeg G., Gonda A., Merilä J. (2009). Evolution of gigantism in nine-spined sticklebacks. Evolution 63:3190 3200 .

Hodges K. E., Stefan C. I., Gillis E. A. (1999). Does body condition affect fecundity in a cyclic population of snowshoe hares? Can. J. Zool. 77:1-6.

Holt S. J. (2004). Foreword to the 2004 printing of Beverton, R. J. H. and Holt, S. J., On the dynamics of exploited fish populations. The Blackburn Press, New Jersey.

Hörnfeldt B. (1994). Delayed density dependence as a determinant of vole cycles. Ecology 73:791-806.

Hudson M. R., Francis C. M., Campbell K. J., Downes C. M., Smith A. C., Pardieck K. L. (2017). The role of the North American Breeding Bird Survey in conservation. The Condor 119:526-545.

Hutchinson G. E. (1948). Circular causal systems in ecology. Ann. N.Y. Acad. Sci. 50:221-246.

Keith L. B. (1963). Wildlife's ten year cycle. University of Wisconsin Press, Madison.

Kendall W. L., Peterjohn B. G., Sauer J. R. (1996). Firsttime obesrver effects in the North American Breeding Bird Survey. Auk 113:823-829.

Kingsolver J. G. Pfennig D. W. (2004). Individual-level selection as a cause of Cope's rule of phylogenetic size increase. Evolution 56:1608-1612.

Krebs C. J. (1996). Population cycles revisited. J. Mamm. $77: 8-24$.

Krebs C. J., Gaines M. S., Keller B. L., Myers J. H., Tamarin R. H. (1973). Population cycles in small rodents. Science 179:35-41.

Krebs C. J. Myers J. (1974). Population cycles in small mammals. Ad. Ecol. Res. 8:267-399.

Kupferschmidt K. (2021). Fast-spreading U.K. virus variant raises alarm. Science 371:9-10.

Lambin X., Bretagnolle V., Yoccoz N. G. (2006). Vole population cycles in northern and southern Europe: Is there a need for different explanations for single pattern? J. Anim. Ecol. 75:340-349.

Law R. (2000). Fishing, selection, and phenotypic evolution. ICES J. Marine Sci. 57:659-668.

Le Boeuf B. J. Briggs K. T. (1977). The cost of living in a seal harem. Mammalia 41:167-195.

Lidicker W. Z. Ostfeld R. S. (1991). Extra-large body size in California voles: Causes and fitness consequences. Oikos 61:108-121.

Link W. A. Sauer J. R. (1998). Estimating population change from count data: Application to the North American Breeding Bird Survey. Ecol. Appl. 8:258-268.

Link W. A. Sauer J. R. (2002). A hierarchical analysis of population change with application to Cerulean Warblers. Ecology 83:2832-2840.

Link W. A., Sauer J. R., Niven D. K. (2020). Model selection for the North American Breeding Bird Survey. Ecology $83: 2832-2840$

Lotka A. J. (1925). Elements of physical biology. Williams and Wilkins, Baltimore.

Malthus T. R. (1798). An essay on the principle of population. Johnson, London.

Matthiopoulos J., Moss R., Mougeot F., Lambin X., Redpath S. M. (2003). Territorial behaviour and population dynamics in red grouse Lagopus lagopus scoticus. II. Population models. J. Anim. Ecol. 72:1083-1096.

May R. M. (2020). What determines population density?. In: Dobson A., Holt R. D., Tilman D. (eds). Unsolved problems in ecology: Princeton University Press, Princeton, pp 67-75.

McCullough D. R. (1979). The George River Deer Herd: Population ecology of a k-selected species. Univ. Michigan Press, Ann Arbor.

Mihok S. Boonstra R. (1992). Breeding performance in captivity of meadow voles (Microtus pennsylvanicus) from decline- and increase-phase populations. Can. J. Zool. 70:1561-1566.

Mihok S., Turner B. N., Iverson S. L. (1985). The characterization of vole population dynamics. Ecol. Monogr. 55:399-420.

Mousseau T. A. Fox C. W. (1998). The adaptive significance of maternal effects. Trends Ecol. Evol. 13:403-407.

Murdoch W. W. McCauley E. (1985). Three distinct types of dynamic behavior shown by a single planktonic system. Nature 316:628-630.

Myers J. H. (1990). Population cycles of western tent caterpillars: experimental introductions and synchrony of fluctuations. Ecology 71:986-995.

Naumov S. P., Gibet L. A., Shatalova S. (1969). Dynamics of sex ratio in respect to changes in numbers of mammals. Zh. Obshch. Biol. 30:673-680.

Nee S., Read A. F., Greenwood J. J. D., Harvey P. H. (1991). The relationship between abundance and body size in british birds. Nature 351:312-313.

Niemuth N. D., Estey M. E. an Fields S. P., Wangler B., Bishop A. A., Moore P. J., Grosse R. C., Ryba A. J. (2017). Developing spatial models to guide conservation of grassland birds in the U.S. Northern Great Plains. The Condor 119:506-525.

Norrdahl K. Korpimäki E. (2002). Changes in individual quality during a 3 -year population cycle of voles. Oecologia 130:239-249.

Oli M. K. (2003a). Population cycles of small rodents are caused by specialist predators: or are they? Trends Ecol. Evol. 18:105-107. 
Oli M. K. (2003b). Response to Korpimäki et al.: vole cycles and predation. Trends Ecol. Evol. 18:495-496.

Pearl R. Reed L. J. (1920). On the rate of growth of the population of the United States since 1790 and its mathematical representation. Proc. Nat. Acad. Sci. 6:275288.

Pella J. Tomlinson P. (1969). A generalized stock production model. Trop. Tuna. Comm. Bull. 13:419-496.

Peters R. H. (1983). The ecological implication of body size. Cambridge University Press, Cambridge.

Piertney S. B., Lambin X., Maccoll A. D. C., Lock K., Bacon P. J., Dallas J. F., Leckie F., Mougeot F., Racey P. A., Redpath S., Moss R. (2008). Temporal changes in kin structure through a population cycle in a territorial bird, the red grouse Lagopus lagopus scoticus. Mol. Ecol. 17:2544-2551.

Ramsayer J., Kaltz O., Hochberg M. E. (2013). Evolutionary rescue in populations of Peudomonas fluoresens across an antibiotic gradient. Evol. Appl. 6:608-616.

Reiss M. J. (1989). The allometry of growth and reproduction. Cambridge University Press, Cambridge.

Reznick D. N., Butler I. M. J., Rodd F. H., Ross P. (1996). Life-history evolution in guppies (Poecilia reticulata) 6. differential mortality as a mechanism for natural selection. Evolution 50:1651-1660.

Robbins C. S., Bystrak D., Geissler P. H. (1986). The breeding bird survey: its first fifteen years, 1965-1979. U.S. Fish and Wildlife Service Resource Publication 157.

Rosenberg K. V., Blancher P. J., Stanton J. C., Panjabi A. O. (2017). Use of North American Breeding Bird Survey data in avian conservation assessments. The Condor 119:594-606.

Rossetto M., De Leo G., Bevacqua D., Micheli F. (2012). Allometric scaling of mortality rates with body mass in abalones. Oecologia 168:989-996.

Saccheri I. Hanski I. (2006). Natural selection and population dynamics. Trends Ecol. Evol. 21:341-347.

Sauer J. R., Fallon J. E., Johnson R. (2003). Use of North American Breeding Bird Survey data to estimate population change for bird conservation regions. J. Wild. Manag. 67:372-389.

Sauer J. R., Niven D. K., Hines J. E., Ziolkowski D. J., Pardieck K. L., Fallon J. E., Link W. A. (2017a). The North American Breeding Bird Survey, Results and analysis 1996 - 2015. Version 2.07.2017. USGS Patuxent Wildlife Research Center, Laurel, Maryland, Available at www.mbr-pwrc.usgs.gov/bbs/bbs.html.

Sauer J. R., Pardieck K. L., Ziolkowski D. J., Smith A. C., Hudson M. R., Rodriguez V., Berlanga H., Niven D. K., Link W. A. (2017b). The first 50 years of the North American Breeding Bird Survey. The Condor 119:576-593.

Sauer J. R., Peterjohn B. G., Link W. A. (1994). Obesrver differences in the North American Breeding Bird Survey. Auk 111:50-62.
Schoener T. W. (2011). The newest synthesis: understanding the interplay of evolutionary and ecological dynamics. Science 331:426-429.

Semeonoff R. Robertson F. W. (1968). A biochemical and ecological study of plasma esterase polymorphism in natural populations of the field vole, Microtus agrestis L. Biochem. Genet. 1:205-227.

Simchuk A. P., Ivashov A. V., Companiytsev V. A. (1999). Genetic patters as possible factors causing population cycles in oak leafroller moth, Tortrix viridana L. For. Ecol. Manage. 113:35-49.

Sinclair A. F., Swain D. P., Hanson J. M. (2002). Disentangling the effects of size-selective mortality, density, and temperature on length-at-age. Can. J. Fish. Aquat. Sci. 59:372-382.

Sinclair A. R. E. (1989). Population regulation in animals. In: Cherrett J. M. (ed). Ecological concepts. The contribution of ecology to an understanding of the natural world: Blackwell Scientific Publications, Oxford, pp 197-241.

Sinervo B., Svensson E., Comendant T. (2000). Density cycles and an offspring quantity and quality game driven by natural selection. Nature 406:985-988.

Smith A. C., Hudson M. R., Downes C. M., Francis C. M. (2014). Estimating breeding bird survey trends and annual indicies for Canada: How do the new hiearchical Bayesian estimates differ from previous estimates? Can. F.-Nat. 128:119-134.

Smith C. C. Fretwell S. D. (1974). The optimal balance between size and number of offspring. Am. Nat. 108:499506.

Stearns S. C. (1992). The evolution of life histories. Oxford University Press, Oxford.

Stenseth, N. C. \& Ims, R., eds (1993). The biology of lemmings. Academic Press, San Diego.

Stenseth N. C., Viljugrein H., Saitoh T., Hansen T. F., Kittilsen M. O., Bølviken E., Glöckner F. (2003). Seasonality, density dependence, and population cycles in Hokkaido voles. Proc. Nat. Acad. Sci. 100:1147811483.

Stewart J. D., Durban J. W., Knowlton A. R., Lynn M. S., Fearnbach H., Barbaro J., Perryman W. L., Miller C. A., Moore M. J. (2021). Decreasing body lengthts in North Atlantic right whales. Curr. Biol. 31:1-6.

Thompson J. N. (1998). Rapid evolution as an ecological process. Trends Ecol. Evol. 13:329-332.

Turchin P. Taylor A. D. (1992). Complex dynamics in ecological time series. Ecology 73:289-305.

Turcotte M. M., Reznick D. N., Hare J. D. (2011a). The impact of rapid evolution on population dynamics in the wild: experimental test of eco-evolutionary dynamics. Ecol. Lett. 14:1084-1092.

Turcotte M. M., Reznick D. N., Hare J. D. (2011b). Experimental assessment of the impact of rapid evolution on population dynamics. Evol. Ecol. Res. 13:113-131. 
UN (1982). United Nations Convention on the Law of the Sea, 10 December 1982. http://www.un.org .

Verhulst P. F. (1838). Notice sur la loi que la population suit dans son accroissement. Corresp. Math. Phys. 10:113121.

Volterra V. (1926). Variazioni e fluttuazioni del numero d'individui in specie animali conviventi. Mem. Acad. Lincei. 2:31-113.

Watson A., Moss R., Parr R., Mountford M. D., Rothery P. (1994). Kin landownership, differential aggression between kin and non-kin, and population fluctuations in red grouse. J. Anim. Ecol. 63:39-50.

Witteman G. J., Redfearn A., Pimm S. L. (1990). The extent of complex population changes in nature. Evol. Ecol. 4:173-183.

Witting L. (1995). The body mass allometries as evolutionarily determined by the foraging of mobile organisms. J. theor. Biol. 177:129-137, https://doi.org/10.1006/jtbi.1995.0231.

Witting L. (1997). A general theory of evolution. By means of selection by density dependent competitive interactions. Peregrine Publisher, Århus, 330 pp, URL http://mrLife.org.

Witting L. (2000a). Interference competition set limits to the fundamental theorem of natural selection. Acta Biotheor. 48:107-120, https://doi.org/10.1023/A:1002788313345.

Witting L. (2000b). Population cycles caused by selection by density dependent competitive interactions. Bull. Math. Biol. 62:1109-1136, https://doi.org/10.1006/bulm.2000.0200.

Witting L. (2002). Evolutionary dynamics of exploited populations selected by density dependent competitive interactions. Ecol. Model. 157:51-68, https://doi.org/10.1016/S0304-3800(02)00172-2.

Witting L. (2003). Reconstructing the population dynamics of eastern Pacific gray whales over the past 150 to 400 years. J. Cetacean Res. Manage. 5:45-54.

Witting L. (2008). Inevitable evolution: back to The Origin and beyond the 20th Century paradigm of contingent evolution by historical natural selection. Biol. Rev. 83:259-294, https://doi.org/10.1111/j.1469185X.2008.00043.x.

Witting L. (2013). Selection-delayed population dynamics in baleen whales and beyond. Pop. Ecol. 55:377-401, http://dx.doi.org/10.1007/s10144-013-0370-9.

Witting L. (2017a). The natural selection of metabolism and mass selects allometric transitions from prokaryotes to mammals. Theor. Pop. Biol. 117:23-42, http://dx.doi.org/10.1016/j.tpb.2017.08.005.

Witting L. (2017b). The natural selection of metabolism and mass selects lifeforms from viruses to multicellular animals. Ecol. Evol. 7:9098-9118, http://dx.doi.org/10.1002/ece3.3432.

Witting L. (2020). The natural selection of metabolism ex- plains curvature in fossil body mass evolution. Evol. Ecol. 47:56-75, http://dx.doi.org/10.1007/s11692020-09493-y.

Witting L. (2021a). On the natural selection causality of bird life histories. Preprint in prep for bioRxiv .

Witting L. (2021b). Life history distributions reveal natural selection in birds and mammals. Preprint in prep for bioRxiv .

Witting L. (2021c). Life histories of 9,488 bird and 4,865 mammal species. Preprint in prep for bioRxiv .

Witting L. (2021d). On the natural selection causality of mammal life histories. Preprint in prep for bioRxiv .

Wynne-Edwards V. C. (1962). Animal dispersion in relation to social behavior. Oliver \& Boyd, Edinburgh.

Wynne-Edwards V. C. (1986). Evolution through group selection. Blackwell Scientific Publications, Oxford.

Wynne-Edwards V. C. (1993). A rationale for group selection. J. theor. Biol. 162:1-22. 